$\mathcal{G S}_{\text {http://dx.doi.org/10.3765/sp.10.10 }}^{\text {Semantics \& Pragmatics Volume 10, Article 10, } 2017}$

This is an EARLY ACCESS version of

Del Prete, Fabio \& Sandro Zucchi. 2017. A unified non monstrous semantics for third person pronouns. Semantics and Pragmatics 10(10). http://dx. doi.org/10.3765/sp.10.10.

This version will be replaced with the final typeset version in due course. Note that page numbers will change, so cite with caution. 
EARLY ACCESS

\title{
A unified non monstrous semantics for third person pronouns*
}

\author{
Fabio Del Prete \\ CLLE-ERSS \\ CNRS et Université de Toulouse II
}

\author{
Sandro Zucchi \\ Dipartimento di Filosofia \\ Università degli Studi di Milano
}

\begin{abstract}
It is common practice in formal semantics to assume that the context specifies an assignment of values to variables and that the same variables that receive contextually salient values when they occur free may also be bound by quantifiers and $\lambda \mathrm{s}$. These assumptions are at work to provide a unified account of free and bound uses of third person pronouns, namely one by which the same lexical item is involved in both uses. One way to pursue this account is to treat quantifiers and $\lambda \mathrm{s}$ as monsters in Kaplan's sense. We argue that this move should be avoided and explore an alternative route based on the idea that there is a variable assignment coordinate in the context and a variable assignment coordinate in the circumstance of evaluation, with the definition of truth in context identifying them. One fundamental challenge that arises in pursuing a unified account is to explain the difference in the way the gender presuppositions of bound and free pronouns project. The proposal that emerges from the attempt to meet this challenge is a non-indexical account of free third person pronouns and a new conception of the role and structure of assignment functions.
\end{abstract}

Keywords: context, indexicals, monsters, quantification, pronouns, gender presuppositions

\section{A common practice and a natural move}

It is common practice in formal semantics to assume the following:

(i) context specifies, among other pieces of information, an assignment of values to variables.

This assumption is invoked, for example, in the semantic analysis of Hittite relative clauses (Bach \& Cooper 1977), deictic pronouns (Kaplan 1989, Heim \& Kratzer

* We thank Nicholas Asher, Luca Barlassina, Marco Santambrogio, Philippe Schlenker, Yasutada Sudo for feedback on previous versions of this paper. In its present form, the paper owes much to the detailed comments of three anonymous referees of this journal and to the help of one of its associate editors, Magdalena Kaufmann. 
1998), and so-called "unarticulated constituents" (Stanley 2000). All these analyses assume that Logical Forms (LFs) of natural language sentences may contain free variables whose values are contextually provided. It is also customarily assumed that

(ii) the variables that receive contextually salient values when they occur free may be bound when they occur in the scope of quantifiers and $\lambda \mathrm{s}$ bearing the same index.

While some of the linguistic constructions mentioned above also admit of alternative accounts that make no reference to variables of this kind, in the case of third person pronouns a powerful reason for making assumptions (i)-(ii) is the desirability of accounting for their bound and indexical occurrences by supposing that the same lexical item is involved. According to this view, for example, (1) and (2) contain the same lexical item "he $i$ ", whose denotation depends on a variable assignment (although the semantics of "every" requires one to consider alternative assignments to determine truth):

(1) $\mathrm{He}_{i}$ is intelligent.

(2) Every boy ${ }_{i}$ likes a girl that he ${ }_{i}$ met at school.

Since, in English and in several other languages, third person pronouns that occur free are not phonologically distinct from third person pronouns that occur bound, it is clearly desirable to adopt a uniform semantic account, which is what assumptions (i)-(ii) above pave the way to.

If one analyzes third person pronouns in this way, a natural move (one which, for example, Heim \& Kratzer 1998: 243 seem to suggest) is to regard the variable assignment involved in spelling out the interpretations of the quantifiers and the $\lambda$-operator as a coordinate of the context of utterance. If this move is made, the semantic clause for universally quantified formulae should have form (3), where $c_{g}$ is the assignment of the context $c$ :

$\llbracket \forall v \varphi \rrbracket_{M, c, w, t}=1$ iff $\llbracket \varphi \rrbracket_{M, c^{\prime}, w, t}=1$ for every $c^{\prime}$ such that $c_{g}^{\prime}$ differs from $c_{g}$ at most for the value that $c_{g}^{\prime}$ assigns to $v$ and $c^{\prime}$ agrees with $c$ on all other coordinates.

The semantic clause for the $\lambda$-operator should be stated along similar lines:

$\llbracket \lambda v \varphi \rrbracket_{M, c, w, t}=$ the function $f$ from the domain $\mathrm{D}$ of $\mathrm{M}$ to $\{0,1\}$ such that for every $a \in \mathrm{D}, f(a)=1$ iff $\llbracket \varphi \rrbracket_{M, c^{\prime}, w, t}=1$, where $c^{\prime}$ is such that $c_{g}^{\prime}$ assigns $a$ to $v$ and assigns the same values as $c_{g}$ to all other variables, and $c^{\prime}$ agrees with $c$ on all other coordinates. 
Unified semantics for pronouns

As Zimmermann (1991) and, more recently, Rabern (2013) point out, one consequence of this way of stating the semantics of quantifiers is that they are Kaplanian monsters (Kaplan 1977). Indeed, the universal quantifier in (3) meets Kaplan's definition of monster, by which a monster is any operator $O$ such that $\llbracket O \varphi \rrbracket_{M, c, w, t}$ depends on $\llbracket \varphi \rrbracket_{M, c^{\prime}, w, t}$, for some $c^{\prime} \neq c$. For the same reason, the $\lambda$-operator in (4) also qualifies as a monster.

\section{Reasons to beware}

The proposal for a semantic analysis of quantifiers and $\lambda$ 's that we have outlined in the previous section is summed up in (5):

a. variable assignments are contextual coordinates,

b. the interpretations of the universal quantifier and the $\lambda$-operator are spelled out as in (3)-(4).

It is clear that, if one takes step (5), monsters are much more widespread in natural languages than one might think. In addition to languages displaying shifted indexicals corresponding to "I", "you", "here", and "yesterday" in propositional attitude reports, which initially fueled the supposition that monsters exist in natural languages (Schlenker 2003, Anand \& Nevins 2004), quantifier binding and constructions that make use of the $\lambda$-operator would also involve monsters.

To see how radical a step (5) is, consider (1)-(2) again:

(1) [Pointing to a salient human male.] $\mathrm{He}_{i}$ is intelligent.

(2) Every boy likes a girl that he $_{i}$ met at school.

In view of the fact that (2) contains the pronoun "he", which acts as an indexical in (1), one may be tempted to accept the consequence that (2) is a case of indexical shift after all, hence a monster. But now consider (6):

(6) John saw every man.

According to some, the interpretation of (6) is achieved by raising the quantified NP "every man" to get a structure in which the quantified NP binds the trace left behind by raising:

(7) $\quad[\text { Every man }]_{i}$ John saw $t_{i}$

If "every" in (7) is interpreted as involving a quantification over contextual assignments like " $\forall$ " in (3), the consequence is that (6) is a case of context shift, thus a monster. But (6), unlike (2), contains no expression that is indexical or ever behaves 
like one! ${ }^{1}$ Of course, one might claim that the interpretation of "every" in underlying LFs like (7), unlike the interpretation of "every" in the LF of (2), is not given by clause (3). However, this would involve positing different devices to interpret the universal quantifications in (6) and (2). It would involve, moreover, quantifying over contexts for (8) but not for (6):

Every $\operatorname{man}_{i}$ is such that John saw $\operatorname{him}_{i}$.

We take it that, other things being equal, such a consequence would be undesirable. Thus, taking step (5) plausibly leads one to the radical conclusion that (6) is monstrous. While this consideration is not a knockdown argument against regarding quantifiers and $\lambda \mathrm{s}$ as context shifters, it gives a reason not to take this step lightly and to consider alternative analyses.

A further consideration against step (5) is raised by the account in Kratzer 2009 of local and long distance binding of fake indexicals. Consider the German sentences in (9):

a. Wir sind die einzigen, die unseren Sohn versorgen.

'We are the only ones who are taking care of our son.'

b. Du bist der einzige, der deinen Aufsatz versteht.

'You are the only one who understands your paper'.

c. Du bist der einzige, der glaubt, dass jemand deinen Aufsatz versteht. 'You are the only one who thinks that somebody understands your paper'.

While (9a) allows a bound variable reading which entails that nobody but us takes care of their sons, (9b) lacks a bound variable reading implying that nobody but you understands his paper. Kratzer suggests that the bound variable reading of (9a) depends on the fact that the possessive "unseren" (our) in (9a) is born in the syntax as a mere index (a minimal pronoun) and acquires its features by transmission at PF from the verbal functional head hosting the $\lambda$-operator that binds it, which makes

1 In response to our observation that a monstrous treatment of "every" requires treating (6) as a case of context shift, although no indexical is present, an anonymous reviewer points out that logophoric pronouns never behave like indexicals and still a treatment in terms of context-shift is plausible. Notice however, that logophoric pronouns, as Clements (1975: 172-73) pointed out, "are restricted to reportive contexts transmitting the words or thought of an individual... other than the speaker or narrator." This makes it plausible to treat them as a case of context-shift, precisely because they may be treated by means of the same device that accounts for shifted indexicals in propositional attitude contexts, namely the quantification on contexts introduced by propositional attitude verb. The interpretation of (7), however, does not involve a reported utterance relative to whose context the quantifier trace " $t_{i}$ " may be evaluated and there is no independent reason to suppose that assignments of values to traces are the result of context shift. 
these features unavailable for semantic interpretation. The lack of the bound reading for $(9 b)$, on the other hand, depends on the fact that in this case Kratzer's feature transmission mechanism produces a feature set for "deinen" (your) that cannot be spelled out, thus the possessive must be born with all its features and can only be interpreted as referring to the addressee. Since the same feature transmission mechanism also predicts that "deinen" should be referential in (9c), appeal to minimal pronouns cannot account for the bound variable reading in this case. Kratzer suggests that the possessive in (9c) is a genuine indexical and gets its interpretation as a result of context shift. In particular, the desired reading of (9c) is obtained by adopting Cable's (2005) idea that alongside with regular $\lambda$-operators the grammar makes it available indexical $\lambda$-operators, which may bind first and second person pronouns by shifting the context:

$\llbracket \lambda[1 s t] /[2 n d] \varphi \rrbracket_{M, c}=\lambda x \llbracket \varphi \rrbracket_{M, c^{\prime}}$, where $c^{\prime}$ is like $c$, except possibly that speaker/hearer $\left(c^{\prime}\right)=\mathrm{x}$.

So, Kratzer's account of local and long distance binding of fake indexicals is based, among other things, on the distinction between context shifting $\lambda$-operators like (10) and regular $\lambda$-operators. Notice, however, that, if we take step (5), both indexical $\lambda$-operators and regular $\lambda$-operators are context shifters. While one might try to restate Kratzer's proposal in terms of different types of context shifting operators, one wonders how plausible it would be to assume that the grammar makes two different types of context shifting devices available for binding. Thus, if one accepts Kratzer's account of fake indexicals, again, it may be desirable to explore alternative analyses that do not treat quantifiers and (regular) $\lambda$ s as context shifters.

To sum up, the above considerations give reasons to be cautious about the step of regarding quantifiers and $\lambda$ s as context shifters. While they do not provide knockdown objections against step (5), they do provide reasons to explore alternative routes that avoid treating quantifiers and (ordinary) $\lambda$-abstraction operators as context shifters. ${ }^{2}$ In the following section, we examine two such routes.

2 Lewis (1980) would object to (5b) on the ground that a context is a location (time, place and world) where a sentence is uttered and not an abstract collection of features that can be shifted one at a time. Under Lewis's view, the validity (truth in all contexts) of Kaplan's sentence "I am here now" follows naturally, while under approaches that treat contexts as abstract collections of features that can be shifted one at a time, the constraint requiring that the speaker of a context be located at the place of the context in the world and time of the context has to be stipulated. Notice, however, that the evidence brought to our attention by Kratzer shows that there may be empirical reasons to reject Lewis's view of contexts. Moreover, Anand \& Nevins (2004) argue, on independent grounds, that the Athabaskan language Slave has a context-shifting operator that rewrites the speaker coordinate of contexts. 
Del Prete \& Zucchi

\section{Doubling the assignment}

We saw in the previous section that, if the assignment is only present as a coordinate of the context, we end up with a monstrous semantics for quantifiers and the $\lambda$ operator. How can we avoid this outcome? One route is the following: keep the assumption that denotation is relative to a context that includes an assignment coordinate $c_{g}$, and assume moreover that denotation is relative to an assignment $g$ which is independent of both the context parameter and the circumstance parameter. In other words, besides the context $c$ and the circumstance $\langle w, t\rangle$, let's assume, as is standard in Kaplan's semantics, a third independent parameter, the assignment $g$. The value of indexically used pronouns will be fixed by the contextual assignment $c_{g}$ (following the insight that their reference is determined by the utterance context), while bound variable pronouns will be assigned a value by the external assignment $g$. The clause for the universal quantifier is now given in the standard way:

$\llbracket \forall v \varphi \rrbracket_{c, g, w, t}=1$ iff $\llbracket \varphi \rrbracket_{c, g^{\prime}, w, t}=1$ for every $g^{\prime}$ which differs from $g$ at most for the value assigned to $v$.

So, the strategy is this: double the assignment, and you'll get no monsters begat by quantifiers. But there is a problem. Under the assumption that free and bound pronouns are given a unified semantics, they should be given the same translations, i.e. they should be represented as variables of the same kind. But then we have no way of distinguishing when the value of the variable translating the pronoun should be fixed by the assignment $c_{g}$ and when it should be fixed by the assignment $g$. Ideally, we would like to get the result that, when the variable is free, it is interpreted as in (12), and when it is bound, it is interpreted as in (13):

$$
\begin{aligned}
\llbracket x_{i} \rrbracket_{c, g, w, t} & =c_{g}\left(x_{i}\right) \\
\llbracket x_{i} \rrbracket_{c, g, w, t} & =g\left(x_{i}\right)
\end{aligned}
$$

But this would amount to giving different semantic clauses for the same item. To get the desired result, we would need to distinguish the variables translating indexically used pronouns from those translating pronouns that are up for binding, e.g. we would have to assume clauses of the following kind (where $x_{i}^{*}$ is meant to be an indexical variable, while $x_{i}$ an ordinary bindable variable):

$$
\begin{aligned}
& \llbracket x_{i}^{*} \rrbracket_{c, g, w, t}=c_{g}\left(x_{i}^{*}\right) \\
& \llbracket x_{i} \rrbracket_{c, g, w, t}=g\left(x_{i}\right)
\end{aligned}
$$

However, this amounts to giving up a unified treatment of bound and free pronouns.

The second route, the one we will take, follows a similar lead: double the assignment. Unlike the first route, however, the assignment external to the context 
is seen as part of the circumstance of evaluation. More precisely, we assume the following:

i. denotation is relative to a context $c$ specifying a variable assignment $c_{g}$, and to a circumstance of evaluation which also includes an assignment $g$ as one of its coordinates;

ii. quantifiers and the $\lambda$-operator alike require evaluating the formulae to which they apply with respect to assignments minimally differing from $g$ (the assignment of the circumstance of evaluation);

iii. the value of third person pronouns is fixed by the assignment $g$ of the circumstance of evaluation;

iv. a sentence is true in a context $c$ if the proposition it expresses in $c$ is true at the time, world, and assignment of the context.

According to assumption ii, quantifiers are not context shifters, since they shift the assignment of the circumstance of evaluation. Moreover, by assumption iii, pronouns are given a unified semantics, since their value is uniformly fixed by the assignment of the circumstance. How can we account for the role played by the context in fixing the reference of free pronouns? This result is achieved by the definition of truth in context given in iv, which identifies the assignment of the circumstance with the assignment of the context.

Before we proceed, note that we are departing here from standard assumptions concerning propositions. In possible world semantics, it is usually assumed that propositions are functions from world-time pairs to truth-values. Hence, they are true or false relative to a world and a time, and the truth of a sentence $S$ in a context $c$ is defined as truth of the proposition expressed by $\mathrm{S}$ in $c$ relative to the world and time of $c$. We assume instead that propositions are functions from assignmentworld-time triples to truth values. Hence, they are true or false relative to a world, a time and an assignment, and the truth of a sentence $S$ in a context $c$ is defined as above. Given that one role of variable assignments in our theory will be to fix the value of free third person pronouns, this means that sentences containing free third person pronouns do not express singular propositions in contexts, contrary to what Kaplan assumes. Zimmermann (1991) mentions this as a reason why the route in i-iv should be rejected. While in this paper we do not give a full defence of the view of propositions emerging from i-iv, we'll argue that the decision to reject the route in i-iv should be reconsidered. We'll show that our proposal correctly captures the semantic interaction of third person pronouns with intensional operators. Moreover, we'll argue that a possible objection based on the semantics of propositional attitude reports against treating propositions in this way can be answered. 
Del Prete \& Zucchi

\section{The plan ahead}

While the route we sketched to provide a uniform account of third person pronouns may seem promising, the task will prove challenging. Following Cooper (1983) and much subsequent work, we will adopt a presuppositional account of gender features ( $\phi$-features). One problem raised for an account of this type is that it is not obvious that the presuppositions introduced by the $\phi$-features project in the same way when the pronouns are free and when they are bound (Heim 2008). According to Cooper, the gender presuppositions triggered by free third person pronouns are sui generis: unlike, e.g., the presuppositions of existence and uniqueness triggered by definite descriptions, they must be satisfied by the referents of the pronouns in the world of the context. This idea, known as the indexical presupposition view, has been recently revived and extended by Yanovich (2010). According to Yanovich, both free and bound uses of third person pronouns exhibit indexical presuppositions. This claim, we will argue, is mistaken: bound occurrences, unlike free occurrences, lack indexical presuppositions. ${ }^{3}$ If we are right, a problem arises: the challenge is to keep the semantics of pronouns uniform while accounting at the same time for the difference in the way their presuppositions project when they are bound and when they are free.

In section 5 below, we present a formal system based on the ideas sketched in section 3, which provides a suitable set up for a presuppositional account of $\phi$-features. In sections 6-7, we present a unified presuppositional semantics for third person pronouns and show how it can account for their free and bound occurrences, and for their interaction with modal operators. In section 8, we raise a problem for the account, which we call the fundamental problem. In section 9, a new version of the formal system is presented, which is designed to solve this problem. Our final proposal is sketched in two steps: first, we present a simple version of the theory to convey the intuitive idea underlying it, then we introduce some changes to improve its empirical coverage. We test the theory further in section 10. In section 11, we show that recent accounts of pronouns, in particular Elbourne $(2005,2008)$ and Kratzer (2009) run into the fundamental problem. In section 12, we sum up the results of our inquiry. In Appendix 1, we present the formal system in its final form.

3 Yet a different position in this respect is taken by Sudo (2012). According to him, gender presuppositions of pronouns work the same as the presuppositions of definite descriptions and other triggers, and the apparent indexical behavior of the presuppositions of pronouns is in fact to be explained in terms of (i) a pragmatic dispreference for local accommodation and (ii) a preference for de re readings. In section 8 , we argue that this position does not account for the behavior of gender presuppositions of pronouns under non epistemic modals. 
Unified semantics for pronouns

5 The language IL

Symbols and formulae An intensional language IL suitable for our purposes will include two types of individual variables, plain variables and presuppositional variables:

$x_{1}, x_{2}, x_{3}, \ldots$ (plain variables)

$x_{1}^{m}, x_{2}^{m}, x_{3}^{m}, \ldots, x_{1}^{f}, x_{2}^{f}, x_{3}^{f}, \ldots, x_{1}^{n}, x_{2}^{n}, x_{3}^{n}, \ldots$ (presuppositional variables)

Let $\mathscr{V}$ be the set of plain variables and $\mathscr{V}^{*}$ the set of variables (plain and presuppositional). Presuppositional variables will translate English third person pronouns (in particular, the variables superscripted with $m, f, n$ will translate, respectively, occurrences of male, female, and neuter pronouns). The language also includes an infinite number of $n$-place predicates (for any $n \geqslant 0$ ), the truth-functional connectives, the quantifier every, and the modal operators $\square, \diamond$. The definition of well-formed formulae (wffs) is done as usual for the truth-functional connectives and modal operators. If $\Phi$ and $\Psi$ are wffs and $v \in \mathscr{V},\ulcorner$ every $v \Phi \Psi\urcorner$ is a wff.

Models A model for IL is a structure $M=<\mathscr{C}, \mathscr{W}, \mathscr{U}, \mathscr{T}, \mathscr{P}, \mathscr{F}>$ such that

i. $\mathscr{C}$ is a nonempty set (the set of contexts), where if $c \in \mathscr{C}$,

(i) $c_{a} \in \mathscr{U}$ (the agent of $c$ )

(ii) $c_{t} \in \mathscr{T}$ (the time of $c$ )

(iii) $c_{p} \in \mathscr{P}$ (the position of $c$ )

(iv) $c_{w} \in \mathscr{W}$ (the world of $c$ )

(v) $c_{g} \in \mathscr{U}^{\mathscr{V}}$ (the assignment of $c$ )

ii. $\mathscr{W}$ is a nonempty set (the set of worlds)

iii. $\mathscr{U}$ is a nonempty set (the set of individuals)

iv. $\mathscr{T}$ is a nonempty set (the set of times)

v. $\mathscr{P}$ is a nonempty set (the set of positions)

vi. $\mathscr{F}$ is a function that to every triple consisting of an $\mathrm{n}$-place predicate $\mathrm{P}^{n}$, a world, and a time, assigns a set of $n$-tuples of members of $\mathscr{U}$.

The definition of model is similar to the one provided by Kaplan, except for the fact that a context also specifies an assignment to the plain individual variables (the elements in the set $\mathscr{V}$ ). 
Denotation We assume that the denotation of an expression is relative to a model, a context of utterance, and a circumstance of evaluation consisting of a variable assignment, a world, and a time. We use " $\llbracket \alpha \rrbracket_{M, c, g, w, t}$ " as short for "the denotation of $\alpha$ in the context $c$ relative to the circumstance $\langle g, w, t>$ ".

Variable assignments are total functions assigning an individual to each plain variable. The denotation of a presuppositional variable is determined by the value of the corresponding plain variable in this way:

$$
\begin{aligned}
& \llbracket x_{i} \rrbracket_{M, c, g, w, t}=g\left(x_{i}\right) . \\
& \llbracket x_{i}^{m} \rrbracket_{M, c, g, w, t}=g\left(x_{i}\right) \text { if } g\left(x_{i}\right) \text { is human and male in } c_{w} \text { at } c_{t} \text {, and it's undefined } \\
& \text { otherwise. } \\
& \llbracket x_{i}^{f} \rrbracket_{M, c, g, w, t}=g\left(x_{i}\right) \text { if } g\left(x_{i}\right) \text { is human and female in } c_{w} \text { at } c_{t} \text {, and it's unde- } \\
& \text { fined otherwise. } \\
& \llbracket x_{i}^{n} \rrbracket_{M, c, g, w, t}=g\left(x_{i}\right) \text { if } g\left(x_{i}\right) \text { is not human in } c_{w} \text { at } c_{t}, \text { and it's undefined } \\
& \text { otherwise. }
\end{aligned}
$$

Notice that, according to (17)-(19), the definedness condition for presuppositional variables requires that the individuals they denote be of the relevant gender at the world and time of the context. We'll come back to this feature in sections 7-8.

The denotations of atomic formulae consisting of a predicate and the required number of variables are specified in this way (where $v_{i} \ldots v_{j}$ are variables, plain or not):

$$
\begin{aligned}
& \text { Suppose } \llbracket v_{i} \rrbracket_{M, c, g, w, t}, \ldots, \llbracket v_{j} \rrbracket_{M, c, g, w, t} \text { are defined. } \\
& \text { Then } \llbracket \mathrm{P}^{n}\left(v_{i}, \ldots, v_{j}\right) \rrbracket_{M, c, g, w, t}=1 \text { if }<\llbracket v_{i} \rrbracket_{M, c, g, w, t}, \ldots, \llbracket v_{j} \rrbracket_{M, c, g, w, t}>\in \mathscr{F}\left(\mathrm{P}^{n}\right)(w)(t) ; \\
& \llbracket \mathrm{P}^{n}\left(v_{i}, \ldots, v_{j}\right) \rrbracket_{M, c, g, w, t}=0 \text { if }<\llbracket v_{i} \rrbracket_{M, c, g, w, t}, \ldots, \llbracket v_{j} \rrbracket_{M, c, g, w, t}>\notin \mathscr{F}\left(\mathrm{P}^{n}\right)(w)(t) .
\end{aligned}
$$

The clause for the denotation of universally quantified formulae is this (where " $g^{\prime}[v] g$ " is short for "assignment $g^{\prime}$ differs from assignment $g$ at most for the value assigned to the variable $v$ "):

a. $\quad$ every $v \Phi \Psi \rrbracket_{M, c, g, w, t}$ is defined only if $\llbracket \Psi \rrbracket_{M, c, g^{\prime}, w, t}$ is defined for every $g^{\prime}$ such that $g^{\prime}[v] g$ and $\llbracket \Phi \rrbracket_{M, c, g^{\prime}, w, t}=1$.

b. $\quad$ if $\llbracket$ every $v \Phi \Psi \rrbracket_{M, c, g, w, t}$ is defined, $\llbracket$ every $v \Phi \Psi \rrbracket_{M, c, g, w, t}=1$ if $\llbracket \Psi \rrbracket_{M, c, g^{\prime}, w, t}=1$ for every $g^{\prime}$ such that $g^{\prime}[v] g$ and $\llbracket \Phi \rrbracket_{M, c, g^{\prime}, w, t}=1$; otherwise $\llbracket$ every $v \Phi \Psi \rrbracket_{M, c, g, w, t}=0$. 
Unified semantics for pronouns

According to (21), the quantifier "every" requires the nuclear scope $\Psi$ to be satisfied relative to assignments of the circumstance of evaluation that satisfy the restrictor $\Phi .{ }^{4}$ Thus, "every" is not a monster, since it does not require the context to shift.

The semantic clause for the possibility operator is specified in this way: ${ }^{5}$

a. $\quad \llbracket \vee \varphi \rrbracket_{M, c, g, w, t}$ is defined only if $\llbracket \varphi \rrbracket_{M, c, g, w^{\prime}, t}$ is defined for all $w^{\prime} \in \mathscr{W}$ that are accessible from $w$.

b. if $\llbracket \triangleright \varphi \rrbracket_{M, c, g, w, t}$ is defined, then:

$\llbracket \diamond \varphi \rrbracket_{M, c, g, w, t}=1$ if $\llbracket \varphi \rrbracket_{M, c, g, w^{\prime}, t}=1$, for some $w^{\prime} \in \mathscr{W}$ that is accessible from $w$;

$\llbracket \diamond \varphi \rrbracket_{M, c, g, w, t}=0$ if $\llbracket \varphi \rrbracket_{M, c, g, w^{\prime}, t}=0$, for all $w^{\prime} \in \mathscr{W}$ that are accessible from $w$.

Truth in context In Kaplan's original system, truth in context is defined as truth at the circumstance that consists of the world and time of the context. Since we assume that circumstances of evaluation are triples consisting of an assignment, a world, and a time, truth in context is defined as truth at the assignment, world, and time of the context:

$\Phi$ is true in a context $c$, in the model $M$, if $\llbracket \Phi \rrbracket_{M, c, c_{g}, c_{w}, c_{t}}=1$

$\Phi$ is false in a context $c$, in the model $M$, if $\llbracket \Phi \rrbracket_{M, c, c_{g}, c_{w}, c_{t}}=0$

4 Notice that clause (21a) is only a necessary condition for definedness. More needs to be added to account for cases like (i), where the restrictor contains a pronoun:

Every student of his 1 wrote a paper (pointing at a woman).

The infelicity of (i) may be accounted for by adding to (21a) the condition that

the restrictor $\Phi$ must be defined for some $g^{\prime}$ such that $g^{\prime}[v] g$.

It would not do to require that $\Phi$ be defined for the original assignment $g$, since this would predict that (iii) would be undefined if $g$ does not assign a human male to the quantifier's variable:

(iii) Every student who likes himself wrote a paper.

Clause (ii), on the other hand, allows for (iii) to be defined in such a case.

5 An observation is in order concerning the semantics of the possibility operator in (22). Karttunen (1974) observes that possibility modals are holes, namely they turn the presuppositions of the sentence in their scope into presuppositions of the whole sentence. Our definedness condition for $\diamond$, on the other hand, requires the sentence in its scope to be defined relative to the worlds accessible from the base world, which means that the presupposition of the sentence in the scope of $\diamond$ need not be satisfied relative to the base world. Notice, however, that Soames 1989 restricts the assumption that modals are holes to epistemic modals. In section 7 below, we will discuss examples of non-epistemic modals for which the definedness condition in (22a) is appropriate. 
Del Prete \& Zucchi

Let's now turn to the interpretation of third person pronouns.

\section{The interpretation of third person pronouns}

We follow Heim and Kratzer's (1998) view that the descriptive content of third person pronouns is presupposed and that the denotation of an expression is defined only if its presupposition is met. ${ }^{6} \mathrm{We}$ assume that occurrences of third person pronouns bear a referential index at LF. We translate "he ${ }_{i}$ ", "she ${ }_{i}$ ", and "it ${ }_{i}$ " as in $(23):^{7}$
a. $\quad$ he $_{i} \Rightarrow x_{i}^{m}$
b. $\quad \operatorname{she}_{i} \Rightarrow x_{i}^{f}$
c. $\quad \mathrm{it}_{i} \Rightarrow x_{i}^{n}$

The LF of (1) is now translated as (24):

$\mathrm{He}_{i}$ is intelligent.

Notice that, by (17)-(19) above, the value of a variable that translates a pronoun is determined by the variable assignment of the circumstance of evaluation. However, by the above definition of truth in context, the value of the free variable in (24) is identified with the value determined by the variable assignment of the context:

6 The notion of presupposition assumed here goes back to Strawson (1950). For a discussion of different notions of presupposition, see Soames (1989).

7 The assumption underlying (23) that "he", "she" and "it" presuppose their referents to be human male, human female and non-human is a simplification in several respects. The claim that masculine pronouns always presuppose male referents is controversial (Sudo 2012: 19 and references therein). Moreover, an anonymous reviewer pointed out to us that "it" does not presuppose non-human referents in (i):

(i) Something is such that it is human.

For the purposes of this paper, we ignore these complications concerning masculine and neuter pronouns.

Finally, as pointed out by Schlenker (2011), sometimes the gender features of third person bound pronouns are not interpreted, as shown by the fact that (ii) is not restricted to female individuals and implies that no one (be they male or female) other than Mary did his or her homework:

(ii) Only Mary did her homework.

Configurations of the kind in (ii) have been the focus of much recent work on pronouns (see Heim 2008, Kratzer 2009 and references therein) and we'll have nothing to say about them here. 
Unified semantics for pronouns

"intelligent $\left(x_{i}^{m}\right)$ " is true in $c$, in the model $M$, if 【intelligent $\left(x_{i}^{m}\right) \rrbracket_{M, c, c_{g}, c_{w}, c_{t}}=1$

if $c_{g}\left(x_{i}\right)$ is human and male and intelligent in $c_{w}, c_{t}$.

Now consider (26):

Every $\operatorname{man}_{i}$ is such that he ${ }_{i}$ runs.

We assume that at LF the quantified DP "every $\operatorname{man}_{i}$ " is raised and, moreover, the quantifier "every" is adjoined to IP and bears the same index as the DP out of which it is moved. The resulting LF for (26) is given in (27):

\section{Every $_{i}\left[\operatorname{man}_{i}\right]\left[\mathrm{t}_{i}\right.$ is such that he ${ }_{i}$ runs $]$}

Assuming that the index on the quantifier and the noun translates as the plain variable " $x_{i}$ ", the translation of (27) is (28):

$$
\text { every } x_{i} \operatorname{man}\left(x_{i}\right) \operatorname{run}\left(x_{i}^{m}\right)
$$

According to the definedness condition for quantified formulae in (21a),

$\llbracket$ every $x_{i} \operatorname{man}\left(x_{i}\right) \operatorname{run}\left(x_{i}^{m}\right) \rrbracket_{M, c, c_{g}, c_{w}, c_{t}}$ is defined

only if $\llbracket \operatorname{run}\left(x_{i}^{m}\right) \rrbracket_{M, c, g^{\prime}, c_{w}, c_{t}}$ is defined for every $g^{\prime}$ such that $g^{\prime}\left[x_{i}\right] c_{g}$ and $\llbracket \operatorname{man}\left(x_{i}\right) \rrbracket_{M, c, g^{\prime}, c_{w}, c_{t}}=1$

only if $g^{\prime}\left(x_{i}\right)$ is human and male at $c_{w}, c_{t}$ for every $g^{\prime}$ such that $g^{\prime}\left[x_{i}\right] c_{g}$ and $\llbracket \operatorname{man}\left(x_{i}\right) \rrbracket_{M, c, g^{\prime}, c_{w}, c_{t}}=1$

only if every individual who is a man at $c_{w}, c_{t}$ is human and male at $c_{w}, c_{t}$.

Notice that the presupposition of the pronoun "he", indicated by definedness condition (29), is trivially satisfied here, since every assignment $g^{\prime}$ that satisfies the restrictor " $\operatorname{man}\left(x_{i}\right)$ " at the world and time of the context is such that the individual that $g^{\prime}$ assigns to $x_{i}$ is male and human at the world and time of the context, thus $g^{\prime}$ satisfies the presupposition of the nuclear scope "run $\left(x_{i}^{m}\right)$ " as well.

\section{Interaction of free pronouns with modal operators}

The interaction of free third person pronouns with modal operators follows the general pattern pointed out by Kaplan for demonstratives. One general feature of demonstratives, according to Kaplan, is this:

(30) the descriptive content of demonstratives holds of their referents in the world and at the time of the context in which they are uttered. 
Let's illustrate the point with an example. Recall the 1980 Summer Olympics, held in the Soviet Union. Italian athlete Pietro Mennea won the gold medal in the 200 meter final. No American runner was competing with him, because of the United States' boycott of the games. Now imagine that Jones, while watching Mennea wearing the gold medal, regretfully utters:

(31) The man wearing the gold medal could have been an American.

One salient reading of (31) is that it could have been the case that an American won the gold medal, if the US had not boycotted the Games. ${ }^{8}$ Compare, however, (31) with sentence (32) below, which contains a complex demonstrative in place of the description:

(32) That man wearing the gold medal could have been an American.

An utterance of (32) in the same context could only mean that it could have been the case that Mennea was American. In other words, the descriptive content of the complex demonstrative "that man wearing the gold medal" must be met by its referent in the context of utterance of (32).

The same is true of the descriptive content of third person pronouns. Indeed, one could not utter (33) below to say of an individual who is not a human male that there is a possible circumstance in which that individual is a human male and an American:

He could have been an American.

In other terms, the descriptive content of "he" must hold of its referent in the context in which (33) is uttered - for example, (33) could be uttered by Jones in the context described above only to mean that the particular human male individual who is Mennea could have been an American. This behavior of the third person pronoun in (33) is predicted by the account we sketched. This depends on the fact that modal operators shift the world of the circumstance of evaluation, while the descriptive content of (the presuppositional variable translating) the pronoun is required (by clauses (17)-(19)) to hold of the pronoun's referent in the world and time of the context.

Let's show how the derivation of (33) works. Assuming that the LF for (33) is translated as (34), we get the desired definedness condition in (35) by which the referent of the pronoun is required to be human and male at the world and time of the context:

$$
\triangleright \text { american }\left(x_{i}^{m}\right)
$$

8 Notice that, under this reading, the possibility modal in (31) behaves as a plug, not as a hole. 
Unified semantics for pronouns

$\llbracket \triangleright$ american $\left(x_{i}^{m}\right) \rrbracket_{M, c, c_{g}, c_{w}, c_{t}}$ is defined

only if $\llbracket x_{i}^{m} \rrbracket_{M, c, c_{g}, w^{\prime}, c_{t}}$ is defined for all $w^{\prime} \in \mathscr{W}$ that are accessible from $c_{w}$ only if $c_{g}\left(x_{i}\right)$ is human and male in $c_{w}, c_{t}$.

\section{The fundamental problem}

The semantics for third person pronouns proposed in section 6 is, in essence, the account of free third person pronouns proposed by Cooper (1983). According to Cooper, these pronouns have indexical gender presuppositions, namely, they presuppose that their descriptive content (i.e., human male, human female, non-human) is satisfied by their referents in the actual world.

Cooper, however, restricts the indexical presuppositions to free pronouns, while the unified account presented in section 6 predicts indexical presuppositions to be triggered across the board - i.e., by free and bound pronouns alike. The problem for the latter account, as we'll see in this section, is that there is evidence from the interaction with modal operators showing that bound pronouns fail to trigger indexical presuppositions. Moreover, as Sudo (2012) points out, bound pronouns also fail to display indexical presuppositions with attitude operators, if one properly controls for such factors as the de relde dicto readings of their binders. We discuss the latter type of cases in section 10.1. Let's now turn to the interaction of bound pronouns with modal operators.

Consider the following example. Suppose that Jones, while watching the 1980 Summer Olympics on tv, regretfully observes that, if the United States had taken part in the Olympics, they would have certainly won some gold medals in boxing. Then, he utters (36):

(36) It could have been that every US gold medalist ${ }_{i}$ had defeated a Russian who challenged that medalist ${ }_{i}$.

For (36) to be true, the descriptive content of the complex demonstrative "that medalist" must be satisfied in the possible world introduced by the possibility modal, while it is not required to be satisfied in the actual world. Consider now the variant of (36) where a pronoun occurs in place of the complex demonstrative:

It could have been that every US gold medalist ${ }_{i}$ had defeated a Russian who challenged $\operatorname{him}_{i}$.

A similar observation is true for (37): intuitively, the descriptive content of the pronoun "him", namely the property of being a human male, must be satisfied in the possible world introduced by the possibility modal, not in the actual world. However, our theory does not predict this. Let's translate "US gold medalist" with " $G$ " and 
"defeats a Russian who challenges him" with " $D\left(x_{i}^{m}\right)$ ". According to the proposal in section 6 ,

$\llbracket \diamond$ every $x_{i} G\left(x_{i}\right) D\left(x_{i}^{m}\right) \rrbracket_{M, c, c_{g}, c_{w}, c_{t}}$ is defined only if, for all $w$ that are accessible from $c_{w}$, 【every $x_{i} G\left(x_{i}\right) D\left(x_{i}^{m}\right) \rrbracket_{M, c, c_{g}, w, c_{t}}$ is defined

only if, for all $w$ that are accessible from $c_{w}, \llbracket D\left(x_{i}^{m}\right) \rrbracket_{M, c, g^{\prime}, w, c_{t}}$ is defined for every $g^{\prime}$ such that $g^{\prime}\left[x_{i}\right] c_{g}$ and $\llbracket G\left(x_{i}\right) \rrbracket_{M, c, g^{\prime}, w, c_{t}}=1$

only if, for all $w$ that are accessible from $c_{w}$, every individual which is a US gold medalist at $w, c_{t}$ is a human male at $c_{w}, c_{t}$.

This prediction is incorrect, since it requires that, for (37) to be true non vacuously, there must be some male human individuals in the actual world such that there is some world in which they are US gold medalists at the 1980 Summer Olympics and they defeat the Russians who challenge them. Clearly, (37) is only about individuals who are US gold medalists at the 1980 Summer Olympics in the counterfactual world of the modal, and it is those individuals who are presupposed to be male humans, not any individuals in the actual world (recall that no US athlete participated in the games).

Two observations are in order concerning this problem. The first is that we cannot solve it simply by modifying the semantics of third person pronouns and requiring that their descriptive content be met at the world and time of the circumstance. This would be a natural way to extend Heim and Kratzer's (1998) treatment of the presuppositions of third person pronouns to an intensional semantics (see Sudo 2012: 41 for an explicit formulation), and in our system it would amount to assuming the following interpretation for the presuppositional variables:

$\llbracket x_{i}^{m} \rrbracket_{M, c, g, w, t}=g\left(x_{i}\right)$ if $g\left(x_{i}\right)$ is human and male in $w$ at $t$, and it's undefined otherwise.

$\llbracket x_{i}^{f} \rrbracket_{M, c, g, w, t}=g\left(x_{i}\right)$ if $g\left(x_{i}\right)$ is human and female in $w$ at $t$, and it's undefined otherwise.

$\llbracket x_{i}^{n} \rrbracket_{M, c, g, w, t}=g\left(x_{i}\right)$ if $g\left(x_{i}\right)$ is not human in $w$ at $t$, and it's undefined otherwise.

However, this interpretation predicts that one should be able to point at a woman and utter (42) below to claim that there is some possible circumstance in which she is a male university professor. The problem is that (42) is not felicitous in a context of this kind.

(42) He could have been a university professor. 
The second observation is that the problem posed by (37) is not generated by our assumption that the variable assignment is both a coordinate of the context and a coordinate of the circumstance of evaluation. Indeed, consider the monstrous counterpart of (21):

a. $\quad$ every $v \Phi \Psi \rrbracket_{M, c, w, t}$ is defined only if $\llbracket \Psi \rrbracket_{M, c^{\prime}, w, t}$ is defined for every $c^{\prime}$ that differs from $c$ at most because $\llbracket v \rrbracket_{M, c^{\prime}, w, t} \neq \llbracket v \rrbracket_{M, c, w, t}$ and such that $\llbracket \Phi \rrbracket_{M, c^{\prime}, w, t}=1$.

b. if «every $v \Phi \Psi \rrbracket_{M, c, w, t}$ is defined, then: $\llbracket$ every $v \Phi \Psi \rrbracket_{M, c, w, t}=1$ if $\llbracket \Psi \rrbracket_{M, c^{\prime}, w, t}=1$ for every $c^{\prime}$ that differs from $c$ at most because $\llbracket v \rrbracket_{M, c^{\prime}, w, t} \neq \llbracket v \rrbracket_{M, c, w, t}$ and such that $\llbracket \Phi \rrbracket_{M, c^{\prime}, w, t}=1$; otherwise $\llbracket$ every $v \Phi \Psi \rrbracket_{M, c, w, t}=0$.

If the assignment is only present as a contextual coordinate, as the monstrous treatment of quantifiers would have it, we still have the option, when specifying the interpretation of third person pronouns, of requiring that their descriptive content be met at the time and world of the context or at the time and world of the circumstance. In the first case, the monstrous theory makes the same wrong prediction about (37) as the proposal in section 6 , in the second case it makes the same wrong prediction as (39) concerning (42). In other words, what generates the problem is the attempt to provide a uniform semantics for third person pronouns whether bound or free, not the choice of a non monstrous account of quantifiers over a monstrous one (we come back to this issue in the next section where we discuss previous accounts of third person pronouns).

This is then, we take it, the fundamental problem that arises for any account that treats bound and free uses of third person pronouns as occurrences of the same lexical items:

The fundamental problem. On the one hand, free uses of third person pronouns provide compelling reasons to assume that the descriptive content of the pronoun should be met in the world of the context. On the other hand, their bound uses show that this need not be the case. ${ }^{9}$

\section{Looking for a solution}

The theory we propose in this section is our attempt to solve the fundamental problem. We sketch our proposal in two steps: first we present a simple version to convey the intuitive idea underlying it, then we introduce some changes to improve its empirical coverage. The basic idea, as we'll see in a moment, is that quantifiers

9 The same point may be made by looking at the behavior of bound and free third person pronouns with belief operators. See section 10.1 for discussion. 
require that the world in which the presupposition of the bound pronoun must be satisfied be the world of the circumstance of evaluation. While this doesn't become visible in extensional contexts, it has an effect in intensional contexts, where the world of the circumstance is shifted away from the world of the context.

\subsection{Modal localization of the assignment}

We defend the idea that the role of assignments is not just to assign individuals to variables, but also to carry information about which world is inhabited by those individuals. ${ }^{10}$ As a first approximation, this idea can be formalized by assuming that assignments are parameterized to possible worlds. We assume the following principle of localization, where $g^{w}$ is an assignment parameterized to the possible world $w$ :

$$
\text { for every } v \in \mathscr{V}, g^{w}(v) \text { is an individual inhabiting } w \text {. }
$$

We keep to our previous assumption that the assignment is initialized by the context (see the definition of truth in context in section 5). However, since assignments are now parameterized to a possible world, we need to say how the world parameter of the contextual assignment is set up. We assume that the contextual assignment is parameterized to the world of the context: the assignment of context $c$ is $c_{g}^{c_{w}}$. Truth in context is now defined thus:

- $\Phi$ is true in a context $c$, in the model $M$, if $\llbracket \Phi \rrbracket_{M, c, c_{g}^{c_{w}}, c_{w}, c_{t}}=1$

- $\Phi$ is false in a context $c$, in the model $M$, if $\llbracket \Phi \rrbracket_{M, c, c_{g}^{c_{w}}, c_{w}, c_{t}}=0$

\subsection{Assignment shifts}

Now that assignments are parameterized to possible worlds, we need to be more explicit on the possible ways the assignment coordinate of the circumstance can be shifted. As before, the assignment will be operated upon by quantifiers (and the $\lambda$-operator). We will now state the semantic clauses for quantified DPs and modal operators by following these assumptions:

- a quantifier binding a variable $v$ introduces variants of the input assignment that (i) may differ from it with respect to the value of $v$ and (ii) are parameterized to the world of the circumstance of evaluation $w$;

10 In our system, the domain $\mathscr{U}$ is the domain of possible individuals, which is constant across worlds. We assume however that each world $w$ is inhabited by individuals belonging to a subset of $\mathscr{U}$, which is the set of individuals that are actual at $w$. 
- modal operators only shift the world-coordinate of the circumstance of evaluation, while they do nothing to the assignment-coordinate of the circumstance.

Constraint (ii) on the output assignments of quantifiers is supposed to account for the observation that a quantified DP in the scope of a modal operator has a domain which is restricted to individuals inhabiting the world introduced by the modal operator.

In stating the semantic clause for the universal quantifier based on these assumptions, some care is needed. In principle, the input assignment for a quantifier $Q_{1}$ need not be parameterized to the world of the context, since, by (ii) above, a higher quantifier $Q_{2}>Q_{1}$ might have parameterized that assignment to the world of the circumstance - and if $Q_{2}$ is in the scope of a modal operator, the world of the circumstance may differ from the world of the context. For example, in (45) below, the quantifier "every cat", if interpreted in the scope of the quantifier "every dog", takes an input assignment parameterized to the world of the circumstance $w$, where $w$ has been introduced by the modal operator translating "it could have been that":

It could have been that every dog loved every cat.

However, the input assignment for a quantifier need not be parameterized to the world of the circumstance either, since it could happen that a modal operator shifts the world of the circumstance while the input assignment for the quantifier remains anchored to the world of the context. This is the case for the quantifier "every dog" in (45), if understood as taking scope over "every cat".

We take these options into account, by specifying the clause for universally quantified formulae as in (46) (where @ is a world and the expression " $g^{\prime w}[v] g^{@}$ " is short for " $g^{\prime w}$ is the assignment identical to $g^{\circledR}$ except for the fact that (i) the world parameter of $g^{\prime w}$ is $w$ and (ii) the individual $g^{\prime w}(v)$ may differ from the individual $g^{@}(v)$ '):

a. $\quad$ eevery $\vee \Phi \Psi \rrbracket_{M, c, g^{\circledR}, w, t}$ is defined only if $\llbracket \Psi \rrbracket_{M, c, g^{\prime}, w, t}$ is defined for every $g^{\prime w}$ such that $g^{\prime w}[v] g^{@}$ and $\llbracket \Phi \rrbracket_{M, c, g^{\prime w}, w, t}=1$.

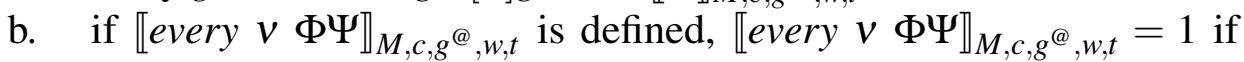
$\llbracket \Psi \rrbracket_{M, c, g^{\prime w}, w, t}=1$ for every $g^{\prime w}$ such that $g^{\prime w}[v] g^{@}$ and $\llbracket \Phi \rrbracket_{M, c, g^{\prime w}, w, t}=$ 1 ; otherwise $\llbracket$ every $v \Phi \Psi \rrbracket_{M, c, g^{\circledR}, w, t}=0$.

The clause for the possibility operator will be essentially the same as the one we gave in section 5, the only difference being that the assignment coordinate is now modally parameterized:

a. $\quad \llbracket \nabla \varphi \rrbracket_{M, c, g^{@}, w, t}$ is defined only if $\llbracket \varphi \rrbracket_{M, c, g^{\circledR}, w^{\prime}, t}$ is defined for all $w^{\prime} \in \mathscr{W}$ that are accessible from $w$. 
b. $\quad$ if $\llbracket \diamond \varphi \rrbracket_{M, c, g^{\circledR}, w, t}$ is defined, then:

$\llbracket \diamond \varphi \rrbracket_{M, c, g^{\circledR}, w, t}=1$ if $\llbracket \varphi \rrbracket_{M, c, g^{\circledR}, w^{\prime}, t}=1$, for some $w^{\prime} \in \mathscr{W}$ that is accessible from $w$;

$\llbracket \nabla \varphi \rrbracket_{M, c, g^{\Theta}, w, t}=0$ if $\llbracket \varphi \rrbracket_{M, c, g^{\circledR, w^{\prime}, t}}=0$, for all $w^{\prime} \in \mathscr{W}$ that are accessible from $w$.

\subsection{Adherence of the presupposition to the world of the assignment}

Another essential ingredient of the solution that we propose is what we call "adherence of the presupposition to the world of the assignment", by which we mean (48):

(48) If the reference of a pronoun pro $_{n}$ is determined by assignment $g^{w}$, the presupposition triggered by pro $_{n}$ must be met in $w$, that is, the individual $g^{w}\left(x_{n}\right)$ must satisfy the relevant presupposition in $w$.

Formally, principle (48) is captured by the following reformulation of the clauses for the denotations of the presuppositional variables translating third person pronouns:

$\llbracket x_{i}^{m} \rrbracket_{M, c, g^{@}, w, t}=g^{@}\left(x_{i}\right)$ if $g^{@}\left(x_{i}\right)$ is human and male in @, and it's undefined otherwise.

$\llbracket x_{i}^{f} \rrbracket_{M, c, g @, w, t}=g^{@}\left(x_{i}\right)$ if $g^{@}\left(x_{i}\right)$ is human and female in @ , and it’s undefined otherwise.

$\llbracket x_{i}^{n} \rrbracket_{M, c, g^{@}, w, t}=g^{@}\left(x_{i}\right)$ if $g^{@}\left(x_{i}\right)$ is non-human in @ , and it's undefined otherwise.

\subsection{Indexical vs. shifty behaviour of pronominal presuppositions}

It's easy to show that the revised system based on modally parameterized assignments can still account for the indexical behaviour of pronominal presuppositions described by Cooper (1983), while enabling one to face the empirical challenge raised by quantifiers in modal contexts which was discussed in section 8 .

Let's begin with the case of the indexical presupposition in the scope of a modal operator corresponding to our example (33), whose LF we have assumed to be translated as in (34):

(33) $\mathrm{He}_{i}$ could have been an American.

(34) $\checkmark$ american $\left(x_{i}^{m}\right)$ 
We now correctly predict that an utterance of (33) in a context $c$ is defined only if the referent of the pronoun is human and male in the world of $c$ and it is true in $c$ if the referent of the pronoun is American in $w^{\prime}, c_{t}$ for some accessible $w^{\prime}$.

Let's turn to the shifty case provided by quantifiers in the semantic scope of modal operators, as shown by the example (37):

It could have been that every US gold medalist ${ }_{i}$ had defeated a Russian who challenged $\operatorname{him}_{i}$.

According to the present proposal, an utterance of (37) in a context $c$ is defined only if, for all accessible $w$, every individual which is a US gold medalist at $w, c_{t}$ is a human male at $w, c_{t}$, and it is true in $c$ if, for some accessible $w$, every individual that is a US gold medalist at $w, c_{t}$ defeats a Russian challenger at $w, c_{t}$. Thus, the new proposal correctly captures the modally bound presupposition of (37), according to which US gold medalists are only presupposed to be human males in the possible world introduced by the possibility operator, not in the world of the context.

\subsection{Modal localization of the assignment again}

We are not done yet. We made the following assumptions to account for the fact that the presuppositions of bound pronouns need not be satisfied at the world of the context: (i) variable assignments are parameterized to a world, and (ii) the denotations of the presuppositional variables " $x_{i}^{m}$ ", " $x_{i}^{f}$ ", " $x_{i}^{n}$ " translating third person pronouns are only defined if the values of the corresponding plain variables are, respectively, male, female, neither male nor female at the world parameterizing the assignment. Since quantifiers identify the world parameter of the assignment with the world of the circumstance of evaluation, the denotation of presuppositional variables need not be defined relative to the world of the context when these variables are in the scope of quantifiers. As we saw, this is a desired consequence in the case of (37) above. However, the proposal we just sketched needs to be improved. Here's why.

Let's assume that "according to $\mathrm{x}$ " is an operator shifting the world coordinate of the circumstance, but not the world of the assignment. Suppose that, while we know that Fabio is male, Jones falsely believes that Fabio is female. Our current proposal correctly predicts that (52) cannot be uttered felicitously in this context to report that, according to Jones, Fabio works in Toulouse:

(52) According to Jones, she (pointing at Fabio) works in Toulouse. 
Indeed, our proposal requires that the presupposition of "she" in (52) be met at the world of the assignment, which, in this case, is the world of the context. ${ }^{11}$ Consider, however, (53):

According to Jones, every student loves her (pointing at Fabio).

Again, this sentence cannot be uttered felicitously in the context considered above. Yet, our current proposal predicts that it should be felicitous if uttered against that background. The reason is this. In (53), the quantifier "every student" is in the scope of the intensional operator "according to Jones", thus the alternative assignments introduced by the quantifier are parameterized to the worlds introduced by the intensional operator, namely to Jones's epistemic alternatives. Therefore, the pronoun "her", though not being bound by the quantifier, ends up being evaluated relative to assignments parameterized to Jones's epistemic alternatives and its presupposition ends up being satisfied (in the context at hand, Jones believes that Fabio is female).

The problem originates from the fact that our system, as it is, requires that the presuppositions of pronouns in the scope of quantifiers must be met at the world of the circumstance not only when these pronouns are bound, as in (37), but also when they are free, as in (53). Thus, in configurations of type (54) below, where the pronoun is free and is in the scope of a quantifier, we predict that the presupposition of the pronoun must be met at the worlds introduced by the intensional operator:

$$
\text { Intensional operator [quantifier ... free pronoun ... ] }
$$

But (53) shows that this prediction is not correct. In order to avoid this problem, the formal system must be revised in such a way that only the denotations of bound presuppositional variables are required to be defined relative to the world of the circumstance of evaluation. This is what we set out to do next.

First, we assume that assignments are not directly parameterized to a world, but to a function $s$ from plain variables to worlds:

$$
g^{S}
$$

Thus, an assignment, besides assigning an individual to each plain variable, also contains "modal" information concerning which world is associated with which variable. For short, let's call the function $s$ from plain variables to worlds the "modal component" of the assignment function. We assume that the assignment provided by the context is specified thus:

11 We are implicitly assuming that, if a proposition $p$ must be true in the world of the context in order for a sentence $S$ to have a truth value, then in order for $S$ to be felicitously utterable in that context, the conversational participants must take for granted that $p$. We'll make this assumption explicit by stating the bridge principle in section 10.3 below. 
Unified semantics for pronouns

$$
c_{g}^{s} \text {, where } s(v)=c_{w} \text { for every } v \in \mathscr{V} .
$$

Namely, the modal component of the contextual assignment associates each variable with the actual world. The principle of localization is now restated as follows:

For every $v \in \mathscr{V}$ and every function $s$ from $\mathscr{V}$ to $\mathscr{W}, g^{s}(v)$ is an individual inhabiting $s(v)$.

This means that, as before, the contextual assignment assigns to each plain variable an individual inhabiting the world of the context, but this is now obtained by parameterizing the assignment to a function from variables to worlds, rather than to a world directly.

The denotation of presuppositional variables is now restated thus:

$\llbracket x_{i}^{m} \rrbracket_{M, c, g^{s}, w, t}=g^{s}\left(x_{i}\right)$ if $g^{s}\left(x_{i}\right)$ is human and male in $s\left(x_{i}\right)$, and it's undefined otherwise.

$\llbracket x_{i}^{f} \rrbracket_{M, c, g^{s}, w, t}=g^{s}\left(x_{i}\right)$ if $g^{s}\left(x_{i}\right)$ is human and female in $s\left(x_{i}\right)$, and it's undefined otherwise.

$\llbracket x_{i}^{n} \rrbracket_{M, c, g^{s}, w, t}=g^{s}\left(x_{i}\right)$ if $g^{s}\left(x_{i}\right)$ is non-human in $s\left(x_{i}\right)$, and it's undefined otherwise.

The clause for the possibility operator " $\diamond$ " stays the same, except for the fact that denotation is now relative to an assignment $g^{s}$ parameterized to a function $s$ from plain variables to worlds.

Let the expression " $g^{\prime s\left[v_{i} \rightarrow w, \ldots, v_{j} \rightarrow w^{\prime}\right]}\left[v_{i}, \ldots, v_{j}\right] g^{s}$ " be short for "the assignment $g^{\prime s\left[v_{i} \rightarrow w, \ldots, v_{j} \rightarrow w^{\prime}\right]}$ is identical to $g^{s}$ except for the fact that (i) $g^{\prime s\left[v_{i} \rightarrow w, \ldots, v_{j} \rightarrow w^{\prime}\right]}$ may differ from $g^{s}$ because its modal component assigns the world $w$ to the variable $v_{i}$, $\ldots$, and the world $w^{\prime}$ to the variable $v_{j}$, and (ii) $g^{s\left[v_{i} \rightarrow w, \ldots, v_{j} \rightarrow w^{\prime}\right]}$ may differ from $g^{s}$ for the individuals assigned to $v_{i}, \ldots, v_{j}$ ". We may now restate the clause for the quantifier "every" as follows:

a. $\quad$ every $v \Phi \Psi \rrbracket_{M, c, g^{s}, w, t}$ is defined only if $\llbracket \Psi \rrbracket_{M, c, g^{\prime s[v \rightarrow w]}, w, t}$ is defined for every $g^{\prime s[v \rightarrow w]}$ such that $g^{\prime s[v \rightarrow w]}[v] g^{s}$ and $\llbracket \Phi \rrbracket_{M, c, g^{\prime s[v \rightarrow w]}, w, t}=1$.

b. if «every $v \Phi \Psi \rrbracket_{M, c, g^{s}, w, t}$ is defined, then: $\llbracket$ every $v \Phi \Psi \rrbracket_{M, c, g^{s}, w, t}=1$ if $\llbracket \Psi \rrbracket_{M, c, g^{\prime s[v \rightarrow w]}, w, t}=1$ for every $g^{\prime s[v \rightarrow w]}$ such that $g^{\prime S[v \rightarrow w]}[v] g^{s}$ and $\llbracket \Phi \rrbracket_{M, c, g^{\prime s[v \rightarrow w]}, w, t}=1$; otherwise $\llbracket$ every $v \Phi \Psi \rrbracket_{M, c, g^{s}, w, t}=0$.

One consequence of (61) is that the quantifier now introduces variants of the input assignment where only the values of variables bound by the quantifier are localized at 
the world of the circumstance. This yields the desired result that only the denotations of bound presuppositional variables are required to be defined relative to the world of the circumstance of evaluation.

Indeed, in the case of (53) the presupposition of "her" must now be satisfied relative to the world of the context and not in Jones's belief worlds:

According to Jones, every student loves her (pointing at Fabio).

To see why this is the case, let's assume that "according to Jones" is translated in IL by the operator $B_{j}$ with the following semantics:

a. $\quad \llbracket B_{j} \varphi \rrbracket_{M, c, g^{s}, w, t}$ is defined only if $\llbracket \varphi \rrbracket_{M, c, g^{s}, w^{\prime}, t}$ is defined for every $w^{\prime} \in$ $\mathscr{W}$ which is a belief world of Jones in $w$.

b. If $\llbracket B_{j} \varphi \rrbracket_{M, c, g^{s}, w, t}$ is defined, then: $\llbracket B_{j} \varphi \rrbracket_{M, c, g^{s}, w, t}=1$ if $\llbracket \varphi \rrbracket_{M, c, g^{s}, w^{\prime}, t}=1$, for every $w^{\prime} \in \mathscr{W}$ which is a belief world of Jones in $w$;

$\llbracket B_{j} \varphi \rrbracket_{M, c, g^{s}, w, t}=0$ if $\llbracket \varphi \rrbracket_{M, c, g^{s}, w^{\prime}, t}=0$, for some $w^{\prime} \in \mathscr{W}$ which is is a belief world of Jones in $w$.

Sentence (53) is now translated as (63) in IL, whose definedness condition is given in (64):

$B_{j}\left(\right.$ every $x_{i} \operatorname{student}\left(x_{i}\right)$ loves $\left.\left(x_{k}^{f}, x_{i}\right)\right)$

$\llbracket B_{j}\left(\right.$ every $x_{i}$ student $\left(x_{i}\right)$ loves $\left.\left(x_{k}^{f}, x_{i}\right)\right) \rrbracket_{M, c, c_{g}^{s}, c_{w}, c_{t}}$ is defined

only if «every $x_{i} \operatorname{student}\left(x_{i}\right)$ loves $\left(x_{k}^{f}, x_{i}\right) \rrbracket_{M, c, c_{g}^{s}, w^{\prime}, c_{t}}$ is defined, for every $w^{\prime} \in \mathscr{W}$ which is a belief world of Jones

only if $\llbracket$ loves $\left(x_{k}^{f}, x_{i}\right) \rrbracket_{M, c, g^{s\left[x_{i} \rightarrow w^{\prime}\right]}, w^{\prime}, c_{t}}$ is defined for every $g^{s\left[x_{i} \rightarrow w^{\prime}\right]}$ such that $g^{s\left[x_{i} \rightarrow w^{\prime}\right]}\left[x_{i}\right] c_{g}^{s}$ and $\llbracket$ student $\left(x_{i}\right) \rrbracket_{M, c, g^{\left[x_{i} \rightarrow w^{\prime}\right]}, w^{\prime}, c_{t}}=1$, for every $w^{\prime} \in \mathscr{W}$ which is a belief world of Jones

only if $\llbracket x_{k}^{f} \rrbracket_{M, c, g^{s\left[x_{i} \rightarrow w^{\prime}\right]}, w^{\prime}, c_{t}}$ is defined for every $w^{\prime} \in \mathscr{W}$ which is a belief world of Jones

only if $g^{s\left[x_{i} \rightarrow w^{\prime}\right]}\left(x_{k}\right)$ is human and female in $s\left[x_{i} \rightarrow w^{\prime}\right]\left(x_{k}\right)$ for every $w^{\prime} \in \mathscr{W}$ which is a belief world of Jones

only if $c_{g}^{s}\left(x_{k}\right)$ is female in $s\left(x_{k}\right)=c_{w}$.

According to the definedness condition which has thus been derived, (53) imposes a constraint on the context by which the denotation of "her" under the contextual assignment must be female in the world of the context. This is the desired result. We now turn to some additional data to see how the theory we outlined fares. 
Unified semantics for pronouns

\section{Testing the theory further}

\subsection{Extension to other intensional operators}

Our theory straightforwardly accounts for the behaviour of third person pronouns in (65) (based on Cooper 1983) and (66) (from Sudo 2012):

(65) Context: we know that Fabio is a man, but Jones believes that Fabio is a woman.
a. ??Jones believes that she $_{i}$ (pointing at Fabio) is a university professor.
b. ??Jones doubts that she ${ }_{i}$ (pointing at Fabio) is a university professor.

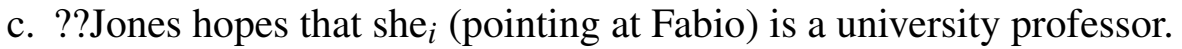
d. ??Jones asked if she ${ }_{i}$ (pointing at Fabio) is a university professor.
e. ??Jones wonders if she ${ }_{i}$ (pointing at Fabio) is a university professor.

(66) Context: John met some new people today and said that some of them are students and some of them are professors. We do not know if he is right about that.
a. John believes that every student ${ }_{i}$ likes herself $_{i}$.
b. John doubts that every student ${ }_{i}$ likes herself $_{i}$.
c. John hopes that every student ${ }_{i}$ likes herself $_{i}$.
d. John asked if every student ${ }_{i}$ likes herself $_{i}$.
e. John wonders if every student likes herself $_{i}$.

Assuming that the semantics of "believe" is similar to that of "according to", the infelicity of (65a) is explained on a par with the infelicity of (52): "she $i$ " is free in the LF of (65a), thus the denotation of (the presuppositional variable translating) "she $i$ " is defined in a context only if the contextual assignment assigns to the plain variable $x_{i}$ an individual who is female in the world of the context. Since the contextual assignment assigns Fabio to $x_{i}$ and we know that Fabio is male, we correctly predict that (65a) cannot be uttered felicitously in the context described in (65). A semantics for "believe" that achieves this result is (67):

a. $\quad$ believe $(\tau, \varphi) \rrbracket_{M, c, g^{s}, w, t}$ is defined only if $\llbracket \varphi \rrbracket_{M, c, g^{s}, w^{\prime}, t}$ is defined, for all $w^{\prime} \in \mathscr{W}$ such that $w^{\prime}$ is a belief world of $\llbracket \tau \rrbracket_{M, c, g^{s}, w, t}$ in $w$.

b. $\quad$ if $\llbracket$ believe $(\tau, \varphi) \rrbracket_{M, c, g^{s}, w, t}$ is defined, then:

$\llbracket \operatorname{believe}(\tau, \varphi) \rrbracket_{M, c, g^{s}, w, t}=1$ if $\llbracket \varphi \rrbracket_{M, c, g^{s}, w^{\prime}, t}=1$, for all $w^{\prime} \in \mathscr{W}$ such that $w^{\prime}$ is a belief world of $\llbracket \tau \rrbracket_{M, c, g^{s}, w, t}$ in $w$;

$\llbracket$ believe $(\tau, \varphi) \rrbracket_{M, c, g^{s}, w, t}=0$ if $\llbracket \varphi \rrbracket_{M, c, g^{s}, w^{\prime}, t}=0$, for some $w^{\prime} \in \mathscr{W}$ such that $w^{\prime}$ is a belief world of $\llbracket \tau \rrbracket_{M, c, g^{s}, w, t}$ in $w$. 
The corresponding lexical entry for "believe" is given in (68) below, where "believe" denotes a relation between and individual and a proposition, which is now a function from $<$ assignment, world, time $>$ triples to truth values. The relation is defined for an individual $x$ and a proposition $p$ only if $p$ is defined for the assignment $g^{s}$ and all the possible worlds that are among $x$ 's doxastic alternatives:

(68) $\llbracket$ believe $\rrbracket_{M, c, g^{s}, w, t}=$ the function $f$ such that, for every individual $x$ and proposition $p$,

a. $\quad f(x, p)$ is defined only if $\forall w^{\prime} \in \mathscr{W}$ such that $w^{\prime}$ is a belief world of $x$ in $w, t, p\left(g^{s}, w^{\prime}, t\right)$ is defined;

b. if $f(x, p)$ is defined, then $f(x, p)=1$ if $\forall w^{\prime} \in \mathscr{W}$ such that $w^{\prime}$ is a belief world of $x$ in $w, t, p\left(g^{s}, w^{\prime}, t\right)=1$; otherwise $f(x, p)=0$.

An appropriate possible world semantics for "doubt", "hope", "ask", and "wonder" will account in the same way for (65b)-(65e), since, like "believe", these verbs do not introduce variants of the input assignment, thus the presupposition of "she", again, must be satisfied relative to the world of the context.

On the other hand, for (66a) we predict (what is observed by Sudo) that the presupposition of "herself" must be satisfied in John's belief worlds, namely (66a) is only felicitous in contexts in which John believes that every student is female. Here's why. As Sudo points out, the context in (66) indicates that the quantifier "every student ${ }_{i}$ " is to be read de dicto. Thus, (66a) will be translated as (69):

$$
\text { believe }\left(j, \text { every } x_{i} \text { student }\left(x_{i}\right) \text { loves }\left(x_{i}^{f}, x_{i}\right)\right)
$$

Formula (69) is defined in a context under these conditions:

【believe $\left(j\right.$, every $x_{i}$ student $\left(x_{i}\right)$ loves $\left.\left(x_{i}^{f}, x_{i}\right)\right) \rrbracket_{M, c, c_{g}^{s}, c_{w}, c_{t}}$ is defined only if «every $x_{i}$ student $\left(x_{i}\right)$ loves $\left(x_{i}^{f}, x_{i}\right) \rrbracket_{M, c, c_{g}^{s}, w^{\prime}, c_{t}}$ is defined, for every $w^{\prime} \in \mathscr{W}$ which is a belief world of Jones in $c_{w}$ only if $\llbracket$ loves $\left(x_{i}^{f}, x_{i}\right) \rrbracket_{M, c, g^{s\left[x_{i} \rightarrow w^{\prime}\right]}, w^{\prime}, c_{t}}$ is defined for every $g^{s\left[x_{i} \rightarrow w^{\prime}\right]}$ such that

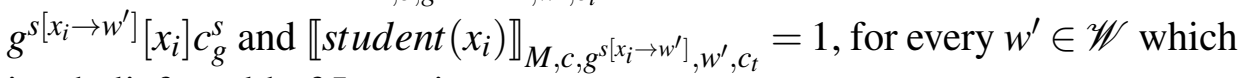
is a belief world of Jones in $c_{w}$ only if $\llbracket x_{i}^{f} \rrbracket_{M, c, g^{s\left[x_{i} \rightarrow w^{\prime}\right]}, w^{\prime}, c_{t}}$ is defined for every $g^{s\left[x_{i} \rightarrow w^{\prime}\right]}$ such that

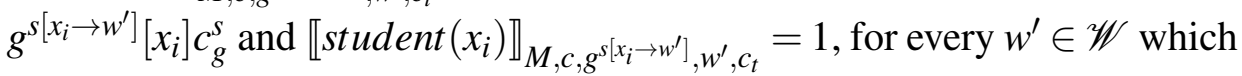
is a belief world of Jones in $c_{w}$ only if for every $g^{s\left[x_{i} \rightarrow w^{\prime}\right]}$ such that $g^{s\left[x_{i} \rightarrow w^{\prime}\right]}\left[x_{i}\right] c_{g}^{s}$ and $\llbracket \operatorname{student}\left(x_{i}\right) \rrbracket_{M, c, g^{s\left[x_{i} \rightarrow w^{\prime}\right]}, w^{\prime}, c_{t}}=1, g^{s\left[x_{i} \rightarrow w^{\prime}\right]}\left(x_{i}\right)$ is female in $s\left[x_{i} \rightarrow w^{\prime}\right]\left(x_{i}\right)$, for every $w^{\prime} \in \mathscr{W}$ which is a belief world of Jones in $c_{w}$ 
Unified semantics for pronouns

only if every individual who is a student in $w^{\prime}$ is female in $w^{\prime}$, for every $w^{\prime}$ which is a belief world of Jones in $c_{w}$.

The interpretation of (66b)-(66e) is accounted for in a similar way, under a suitable analysis of the intensional verbs occurring in these sentences.

Yet another case our theory accounts for is the following, based on Yanovich (2010):

(71) Context: we know that Andrew, a music teacher, does not have any students at the moment, but Andrew himself mistakenly thinks that he has one girl student.

a. According to Andrew , his $_{j}$ student $_{i}$ pushes herself $_{i}$

b. $*$ According to Andrew ${ }_{j}$, his ${ }_{j}$ student $_{i}$ pushes himself $_{i}$.

As indicated in (71a)-(71b), we may only refer to the imaginary female student of Andrew's with a feminine pronoun. The use of a feminine pronoun is accounted for by assuming that "his ${ }_{j}$ student $_{i}$ " is in the scope of the intensional operator "according to Andrew" and is a quantificational DP introducing alternative assignments parameterized to a modal component that assigns a belief world of Andrew's to (the plain variable corresponding to) the variable $x_{i}^{f}$ translating the pronoun "herself ${ }_{i}$ ". In particular, let's assume that the LF of (71a) is given in (72) below, where "the" is the definite description operator:

According to Andrew $j$, [the $\mathrm{x}_{i}\left[\right.$ he $_{j[+ \text { gen }]}$ student $\left._{i}\right]\left[\mathrm{t}_{i}\right.$ pushes herself $\left.\left._{i}\right]\right]$

Moreover, let's assume that an indexed proper name $\alpha_{j}$ is translated as a variable " $x_{j}^{c}$ " whose denotation is defined only in case the assignment assigns to " $x_{j}$ " the individual rigidly denoted by the constant " $c$ " translating $\alpha:{ }^{12}$

12 In particular, we take it that the translation of indexed NPs containing proper names works as in (i) below (where " $a$ " is the constant translating the lexical item "Andrew" and " $x_{i}^{a}$ " a presuppositional variable whose denotation is only defined in case the variable assignment assigns to " $x_{i}$ " the individual rigidly denoted by the constant " $a$ "):

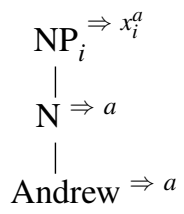

Since we propose that indexed proper names are translated as (a particular kind of) variables, we assume that the option of binding them is either ruled out on pragmatic grounds (having to do with the definedness condition on the variables translating them, which anchors the value of the variable to a fixed individual) or by independent syntactic principles on coindexing. Notice that Cumming (2008) claims that proper names can be bound in some cases. Here, we do not discuss the issue further. 


$$
\llbracket x_{j}^{c} \rrbracket_{M, c, g^{s}, w, t}=g^{s}\left(x_{j}\right) \text { if } g^{s}\left(x_{j}\right)=\llbracket c \rrbracket_{M, c, g^{s}, w, t} \text {, and it's undefined otherwise. }
$$

We may now assume that LF (72) is translated as (74) (where R is a free variable translating $[+$ gen $]$ which denotes a contextually salient relation) ${ }^{13}$ and the interpretation of "the" is specified as in (75):

$$
B_{x_{j}^{a}}\left(\text { the } x_{i}\left(\operatorname{student}\left(x_{i}\right) \wedge R\left(x_{j}^{a}, x_{i}\right)\right) \operatorname{push}\left(x_{i}^{f}, x_{i}\right)\right)
$$

a. $\quad$ the $v \Phi \Psi \rrbracket_{M, c, g^{s}, w, t}$ is defined only if

(i) $\llbracket \Phi \rrbracket_{M, c, g^{\prime s[v \rightarrow w]}, w, t}=1$ for exactly one $g^{\prime s[v \rightarrow w]}$ such that $g^{\prime s[v \rightarrow w]}[v] g^{s}$ and

(ii) $\llbracket \Psi \rrbracket_{M, c, g^{\prime s[v \rightarrow w]}, w, t}$ is defined for every $g^{\prime s[v \rightarrow w]}$ such that

$$
g^{\prime s[v \rightarrow w]}[v] g^{s} \text { and } \llbracket \Phi \rrbracket_{M, c, g^{\prime s[v \rightarrow w]}, w, t}=1 \text {. }
$$

b. $\quad$ if $\llbracket$ the $v \Phi \Psi \rrbracket_{M, c, g^{s}, w, t}$ is defined, then:

$\llbracket$ the $v \Phi \Psi \rrbracket_{M, c, g^{s}, w, t}=1$ if $\llbracket \Psi \rrbracket_{M, c, g^{s}{ }^{[v \rightarrow w]}, w, t}=1$ for every $g^{s{ }^{[v \rightarrow w]}}$ such that $g^{\prime s[v \rightarrow w]}[v] g^{s}$ and $\llbracket \Phi \rrbracket_{M, c, g^{\prime s[v \rightarrow w]}, w, t}=1$;

otherwise $\llbracket$ the $v \Phi \Psi \rrbracket_{M, c, g^{s}, w, t}=0$.

According to these rules, the denotation of (74) is defined only if in each one of Andrew's belief world he has exactly one student and that student is female. The reason is that the operator "the", being in the scope of the quantifier over possible worlds " $B_{x_{j}^{a}}$ ", requires the formula " $p u s h\left(x_{i}^{f}, x_{i}\right)$ " to be defined for every assignment minimally different from the context assignment that assigns to " $x_{i}$ " an individual who is a student of Andrew's in Andrew's belief worlds. Clearly, " $p u \operatorname{sh}\left(x_{i}^{f}, x_{i}\right)$ " cannot be defined for any such assignment unless any student of Andrew's is female in Andrew's belief worlds. Since this is how Andrew's belief worlds are in the context at hand, (71a) is predicted to be fine under the de dicto reading in (74).

On the other hand, the de dicto interpretation of (71b), carried by translation (76) below, is predicted to be infelicitous. Indeed, since in Andrew's belief worlds any student of Andrew's is female, " $p u s h\left(x_{i}^{m}, x_{i}\right)$ " is undefined for every assignment that assigns to " $x_{i}$ " an individual who is a student of Andrew 's in Andrew's belief worlds.

$$
B_{x_{j}^{a}}\left(\text { the } x_{i}\left(\operatorname{student}\left(x_{i}\right) \wedge R\left(x_{j}^{a}, x_{i}\right)\right) \operatorname{push}\left(x_{i}^{m}, x_{i}\right)\right)
$$

Notice, finally, that the de re interpretations of (71a)-(71b), given in (77)-(78), are ruled out in the context described in (71), since they require that there actually exist a student of Andrew's, contrary to what we know.

13 For an analysis of possessive NPs based on this idea, see Partee 1984, 1997. 
Unified semantics for pronouns

$$
\begin{aligned}
& \text { the } x_{i}\left(\operatorname{student}\left(x_{i}\right) \wedge R\left(x_{j}^{a}, x_{i}\right)\right)\left(B_{x_{j}^{a}} \operatorname{push}\left(x_{i}^{f}, x_{i}\right)\right) \\
& \text { the } x_{i}\left(\operatorname{student}\left(x_{i}\right) \wedge R\left(x_{j}^{a}, x_{i}\right)\right)\left(B_{x_{j}^{a}} \operatorname{push}\left(x_{i}^{m}, x_{i}\right)\right)
\end{aligned}
$$

a. John hopes that he will become a woman and he hopes that he will then buy himself a car.

b. *John hopes that he will become a woman and he hopes that she will then buy herself a car.

Let's assume a possible world semantics for "hope" similar to the one for "believe" in (68) above, according to which "hope", like "believe", does not introduce variants of the input assignment:

$\llbracket h o p e \rrbracket_{M, c, g^{s}, w, t}=$ the function $f$ such that, for every individual $x$ and proposition $p$,

a. $\quad f(x, p)$ is defined only if $\forall w^{\prime} \in \mathscr{W}$ such that $w^{\prime}$ is a desire world of $x$ in $w, t, p\left(g^{s}, w^{\prime}, t\right)$ is defined;

b. if $f(x, p)$ is defined, then $f(x, p)=1$ if $\forall w^{\prime} \in \mathscr{W}$ such that $w^{\prime}$ is a desire world of $x$ in $w, t, p\left(g^{s}, w^{\prime}, t\right)=1$; otherwise $f(x, p)=0$

Sentence (79) has the LFs in (81), translated as in (82):

(81) a. John ${ }_{1}$ hopes that he ${ }_{1}$ will become a woman and he ${ }_{1}$ hopes that he will $_{1}$ then buy himself 1 a car

b. John ${ }_{1}$ hopes that he 1 will become a woman and he 1 hopes that she 1 will then buy herself 1 a car

a. $\operatorname{hopes}\left(x_{1}^{j}, \operatorname{become}\left(a\right.\right.$ woman, $\left.\left.x_{1}^{m}\right)\right) \wedge \operatorname{hopes}\left(x_{1}^{m}, \operatorname{buy}\left(\mathbf{x}_{\mathbf{1}}^{\mathbf{m}}, \operatorname{acar}, \mathbf{x}_{\mathbf{1}}^{\mathbf{m}}\right)\right)$

b. $\quad h o p e s\left(x_{1}^{j}, \operatorname{become}\left(a\right.\right.$ woman, $\left.\left.x_{1}^{m}\right)\right) \wedge \operatorname{hopes}\left(x_{1}^{m}, \operatorname{buy}\left(\mathbf{x}_{\mathbf{1}}^{\mathbf{f}}, \operatorname{acar}, \mathbf{x}_{\mathbf{1}}^{\mathbf{f}}\right)\right)$

Notice that the occurrences of the boldfaced variables in (82), which translate the pronouns in the complement of hope, are not bound by a quantifier occurring in the scope of hope. Since hope does not shift the input assignment to variants mapping

14 In Schlenker's original example, the reflexive pronouns in the complement of the attitude verb are bound by PRO, which forces de se readings of the attitude report (see Chierchia 1989):

b. *John hopes PRO to become a woman and he hopes PRO to buy herself a car.

We leave the issue of how to account for de se readings in our system for another occasion. 
the variables to John's desire worlds, the gender presuppositions of the pronouns in the scope of hope must be satisfied by their referent in the world of the context of utterance. As these pronouns are coreferential with the matrix subject pronoun "he" in the second clause, whose referent is presupposed to be male in the world of the context, our account predicts correctly that (79b) should be anomalous, since, unlike (79a), it gives rise to conflicting presuppositions: John should be both male and female in the world of the context. ${ }^{15}$

A potentially challenging example for our account is (83), discussed by Yanovich (2010): ${ }^{16}$

Context: Smith College, one of the Five Colleges of Western Massachusetts, is a women's college. Imagine that Smith has recently gone coed, but not everyone knows about it yet, and Beth reads a letter to some newspaper by a Smith alumna who thinks that Smith is still a women's college. At the same time, Beth already knows that Smith is coed now.

a. This alumna strongly believes it should be made an absolute principle that every Smith College student ${ }_{i}$ meet her ${ }_{i}$ adviser at least twice a week.

Yanovich claims that (83a) is not felicitous if uttered by Beth, who believes that Smith is coed. This indicates that the presupposition of the pronoun "her" is not satisfied locally, i.e. in the alumna's belief worlds, but globally, i.e. in the world of the context. Under our proposal this is not expected, since we predict that local

15 For a discussion of the general issue of bound de re pronouns, see Charlow \& Sharvit 2014. Notice, moreover, that, as Schlenker (2004) pointed out, pronouns in free indirect discourse behave quite differently from the reflexive in (79). This is shown by the contrast in (i) below, where the free indirect discourse in (ib) allows the gender presupposition of "he" to be satisfied in Mary's belief worlds:

(i)

a. [In her dream, Mary ${ }_{i}$ was a cardinal.] Really, she ${ }_{i}$ thought, she $_{i} / \# h_{i}$ had excellent chances of becoming Pope some day.

b. [Mary wrongly believed that Robin was male. In fact, Robin was a woman.] Where was he this morning, for instance? (Mary wondered).

We take it that free indirect discourse is a sufficiently different phenomenon from propositional attitude reports to deserve to be investigated separately.

16 In this example, "her" must be understood as varying over female individuals. The reader should ignore the gender neutral reading of "her", which may be adopted to counteract sexist bias. Plural pronouns may also be introduced for the same purpose, as in (i), where the pronoun "they" allows us to remain neutral about the gender of the caller:

(i) Someone called. They asked for Mary. 
satisfaction of the presupposition should be possible under the de dicto reading of the quantifier "every Smith College student ${ }_{i}$ ". ${ }^{17}$

One important observation in this respect, brought to our attention by Magdalena Kaufmann (p.c.), is that, in fact, local satisfaction of the presupposition of the pronoun "her" is possible for (83a). Indeed, if uttered by Beth in the same context as part of a discourse that raises the salience of the alumna's belief state, as in (84) below, (83a) becomes felicitous:

This alumna believes that Smith is still a women's college. She strongly believes, moreover, that it should be made an absolute principle that every Smith student $_{i}$ meet her ${ }_{i}$ adviser at least twice a week.

Thus, while we have no explanation for why global satisfaction of the presupposition of "her" should be preferred in isolation for (83a), our account still predicts an existing reading of $(83 a)$.

The remaining question is how to account for the possibility that the presupposition of the pronoun "her" is satisfied in the world of the context. Both Yanovich and Sudo suggest that the global presupposition reading of (83a) is due to the quantifier "every Smith College student ${ }_{i}$ " being read $d e r e .{ }^{18}$ Indeed, if we modify (84) by forcing the de re construal of the NP, as in (85), the result is, again, infelicitous if uttered against Yanovich's original scenario:

This alumna believes that Smith is still a women's college. She strongly believes, moreover, of the Smith College students, that it should be made an absolute principle that every one of them meet her ${ }_{i}$ adviser at least twice a week.

This suggests that what is responsible for the infelicity of (83a) is that the NP is read de re.

In our system, if the quantifier is given wide scope with respect to the attitude verb, we correctly predict that the presupposition of the pronoun "her" in (83a) should be satisfied globally. However, if the de re reading is obtained, as we assumed so far, by giving the constituent interpreted de re wide scope with respect to the intensional verb, this generates an unwanted distributive implication for (83a) by which the alumna has a singular belief about each Smith college student. ${ }^{19}$ The scope account of de re readings in propositional attitude contexts, originally considered

17 Similar cases in which the presuppositions of descriptions embedded in the complements of attitude verbs tend to be satisfied globally are discussed in Heim 1992.

18 Neither Sudo nor Yanovich provide an account of why this reading is preferred in isolation.

19 As one reviewer pointed out, the problem we run into here seems to be related to the one raised by the so-called "third reading" of indefinites in attitude contexts observed by Fodor (1970). 
in Quine (1956) and adopted in Montague (1973), has been questioned by several authors also for reasons that are independent from the one we encountered for (83a). ${ }^{20}$ An alternative account which allows one to generate de re readings of quantifiers in the scope of attitude verbs without forcing distributive readings is presented in Keshet $(2008,2011){ }^{21}$ One possible way to avoid the distributive implication for (83a) under the de re reading of "every Smith College student" is to develop our proposal by adopting Keshet's account. We will not try to implement this solution here.

\subsection{Objects of belief}

Apart from the last case described by Yanovich, our account makes correct predictions about the interaction of pronouns with belief operators. Thus, (86) below is true just in case Jones believes of the female individual which in the context of utterance of (86) is the denotation of the pronoun "she" that that individual is a university professor:

Jones believes that she is a university professor.

From this point of view, our theory, although it treats propositions as functions from world-time-assignment triples to truth values, makes exactly the same predictions as theories that treat the proposition expressed in a context by the complement of "believe" in (86) as a singular proposition about the contextually salient female assigned to the pronoun "she". Another way to put the point is that, although our theory treats the verb "believe" in (86) as expressing a relation between an individual and the characteristic function of a set of assignment-world-time triples, what it means for an individual to stand in a relation to such a set of triples is spelled out in terms of the truth in Jones's belief worlds of the singular proposition obtained by assigning to the pronoun the contextually relevant individual. The final result is that the truth-conditions assigned to (86) are the same as those assigned to it in standard possible world semantics.

A potential problem for theories that treat attitude ascriptions as relating the subject of the attitude to open propositions (sets of assignment-world-time triples) is suggested by some observations by Kaplan (1989) (see also Pickel 2013 for discussion). Suppose that George, looking at Thatcher on tv, says to himself "she is a university professor", while Oscar, looking at Anscombe lecturing, says to himself "she is a university professor". Clearly, what George believes is false and what Oscar believes is true. Yet, one might object that, according to our theory, the object

20 For a recent discussion of the problems with the scope account, see Keshet (2008).

21 Other accounts are proposed by Percus (2000), Elbourne (2005, 2008), and Romoli \& Sudo (2008). See Schwager (2009) for some problems with these accounts. 
of George's belief and the object of Oscar's belief are the same, since "she is a university professor" in both contexts expresses the same open proposition: the set of assignment-world-time triples $\langle g, t, w\rangle$ such that the value assigned to "she" by $g$ is a female individual who is a university professor in $t, w$.

We agree that there is a sense in which the object of George's belief in $c$ is the proposition that Thatcher is a university professor and the object of Oscar's belief in $c^{\prime}$ is the proposition that Anscombe is a university professor. Does it follow that our semantics for "believe that" is incorrect? It does not. What follows is that expressions like "the object of x's belief" or "the content of x's belief" in a context $c$ need not pick out the semantic value of a that-clause in $c$, they may pick out instead the value of a that-clause in $c$ relative to the contextual assignment $c_{g}$. As we pointed out above, according to our account the latter value is employed in computing the truth-conditions of belief reports in context, so it is not surprising that we may refer to it. We conclude that the objection we considered need not lead one to reject our view of propositions. ${ }^{22}$

\subsection{Anaphoric pronouns with non c-commanding antecedents}

So far, we have only considered cases in which third person pronouns are either free and their interpretation is provided by the extra-linguistic context of utterance or bound by c-commanding quantifiers. How does the theory fare with pronouns anaphoric to non c-commanding antecedents?

Consider the conditionals in (87), based on Stalnaker (1988):

a. If a woman 1 had proposed the theory Copernicus proposed, she ${ }_{1}$ would have been ignored.

b. If Copernicus ${ }_{1}$ hadn't existed, we would not praise him 1 now.

In (87a), the pronoun "she 1 " in the consequent is construed with the non c-commanding indefinite "a woman 1 " in the antecedent. In (87b), the pronoun "him 1 " in the consequent is construed with the non c-commanding proper noun "Copernicus 1 " in the antecedent. As Stalnaker observes, the pronoun in the consequent of (87a) refers to an individual who only inhabits the counterfactual world(s) in which the antecedent is true, while the pronoun in the consequent of (87b) refers to a real world individual. Let's see how our analysis copes with these data.

Consider (87a) first. As is well-known, the anaphoric relation in (87a) is either analysed as an instance of binding (Kamp 1981, Heim 1982, Groenendijk \& Stokhof

22 It may be argued that there is also a sense in which Oscar and George believe the same thing, namely that the female individual talked about is a university professor. Cumming (2008) suggests that open propositions (in our terms, assignment-world-time triples) may be objects of beliefs, which predicts that Oscar and George believe the same thing. See, however, Pickel (2013) for a criticism of this view. 
1991, and others) or as an instance of e-type anaphora (Evans 1977, 1980, and others). In the latter case, the pronoun is analysed as a definite description at LF, hence as a quantifier, according to the analysis of definite descriptions proposed in (75) above. Thus, while our proposal is compatible with an e-type analysis of (87a) and this analysis is not problematic from our point of view, we do not discuss this option here, since under the e-type analysis the pronoun is not a presuppositional variable at $\mathrm{LF}$, which is the case we want to address.

Let's suppose that the anaphoric relation in (87a) is an instance of binding. We will sketch an analysis based on the assumption that indefinites are non quantificational and are translated as open formulae (Heim 1982, Kamp 1981). ${ }^{23}$ Let's assume with Heim that, at LF, indefinite DPs copy their index on the conditional operator. In this case, (87a) will be represented at LF as (88) (ignoring tense) and translated as (89) (where "W" translates the predicate "woman", "P" the predicate "propose", "I" the predicate "is ignored" and "K" the complex predicate "theory Copernicus proposed"):

the $_{2}$ [theory Copernicus proposes $]_{2}\left[\mathrm{if}_{1}[\mathrm{a} \text { [woman }]_{1}\left[\mathrm{t}_{1}\right.\right.$ proposes $\left.\left.\mathrm{t}_{2}\right]\right]$, [she $\mathrm{sh}_{1}$ is ignored]]

The interpretation of the conditional operator may be stated as in (90), following Heim's idea that, besides introducing a quantification over possible worlds, the conditional is also the source of the universal quantification over individuals: ${ }^{24}$

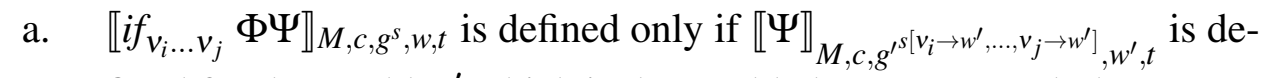
fined for the world $w^{\prime}$ which is the world closest to $w$ such that $\llbracket \exists v_{i} \ldots v_{j} \Phi \rrbracket_{M, c, g^{s}, w^{\prime}, t}=1$ and for every $g^{\prime s\left[v_{i} \rightarrow w^{\prime}, \ldots, v_{j} \rightarrow w^{\prime}\right]}$ such that

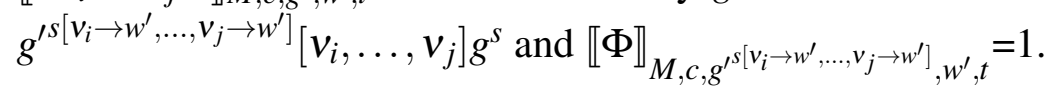

23 Another option, which we don't pursue here, is that indefinites introduce dynamic existential quantifiers, as in Groenendijk \& Stokhof (1991) and others.

24 We assume that the denotation of " $\exists v_{i} \ldots v_{j} \Phi$ ” is defined as follows:

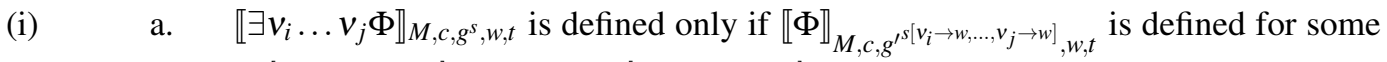
$g^{\prime s\left[v_{i} \rightarrow w, \ldots, v_{j} \rightarrow w\right]}$ such that $g^{\prime s\left[v_{i} \rightarrow w, \ldots, v_{j} \rightarrow w\right]}\left[v_{i}, \ldots, v_{j}\right] g^{s}$.

b. $\quad$ if $\llbracket \exists v_{i} \ldots v_{j} \Phi \rrbracket_{M, c, g^{s}, w, t}$ is defined, then:

$\llbracket \exists v_{i} \ldots v_{j} \Phi \rrbracket_{M, c, g^{s}, w, t}=1$ if $\llbracket \Phi \rrbracket_{M, c, g^{\prime} s\left[v_{i} \rightarrow w, \ldots, v_{j} \rightarrow w\right]}, w, t=1$ for some $g^{\prime s\left[v_{i} \rightarrow w, \ldots, v_{j} \rightarrow w\right]}$ such that $g^{\prime s\left[v_{i} \rightarrow w, \ldots, v_{j} \rightarrow w\right]}\left[v_{i}, \ldots, v_{j}\right] g^{s}$; otherwise $\llbracket \exists v_{i} \ldots v_{j} \Phi \rrbracket_{M, c, g^{s}, w, t}=0$. 
Unified semantics for pronouns

b. if $\llbracket$ if $f_{v_{i} \ldots v_{j}} \Phi \Psi \rrbracket_{M, c, g^{s}, w, t}$ is defined, then:
$\llbracket i f_{v_{i} \ldots v_{j}} \Phi \Psi \rrbracket_{M, c, g^{s}, w, t}=1$ if $\llbracket \Psi \rrbracket_{M, c, g^{\prime} s\left[v_{i} \rightarrow w^{\prime}, \ldots, v_{j} \rightarrow w^{\prime}\right]}, w^{\prime}, t$ $w^{\prime}$ which is the world closest to $w$ such that $\llbracket \exists v_{i} \ldots v_{j} \Phi \rrbracket_{M, c, g^{s}, w^{\prime}, t}=1$ and for every $g^{\prime s\left[v_{i} \rightarrow w^{\prime}, \ldots, v_{j} \rightarrow w^{\prime}\right]}$ such that

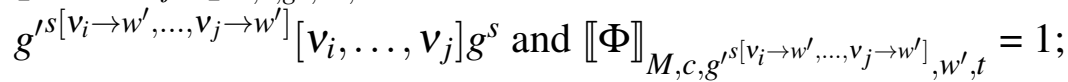

otherwise $\llbracket i f_{v_{i} \ldots v_{j}} \Phi \Psi \rrbracket_{M, c, g^{s}, w, t}=0$.

When no indices are copied on the if-operator, clause (90) reduces to the simple Stalnakerian analysis in (91):

a. $\quad \llbracket$ if $\Phi \Psi \rrbracket_{M, c, g^{s}, w, t}$ is defined only if $\llbracket \Psi \rrbracket_{M, c, g^{s}, w^{\prime}, t}$ is defined, where $w^{\prime}$ is the world closest to $w$ such that $\llbracket \Phi \rrbracket_{M, c, g^{s}, w^{\prime}, t}=1$.

b. if 【if $\Phi \Psi \rrbracket_{M, c, g^{s}, w, t}$ is defined, then: $\llbracket$ if $\Phi \Psi \rrbracket_{M, c, g^{s}, w, t}=1$ if $\llbracket \Psi \rrbracket_{M, c, g^{s}, w^{\prime}, t}=1$, where $w^{\prime}$ is the world closest to $w$ such that $\llbracket \Phi \rrbracket_{M, c, g^{s}, w^{\prime}, t}=1$; otherwise $\llbracket$ if $\Phi \Psi \rrbracket_{M, c, g^{s}, w, t}=0$.

By this analysis, we correctly predict that the descriptive content of the pronoun "she ${ }_{1}$ " in (87a) should be satisfied in the closest world in which a woman proposed the theory that Copernicus actually proposed:

$\llbracket(89) \rrbracket_{M, c, c_{g}^{s}, c_{w}, c_{t}}$ is defined only if:

(i) $\llbracket K\left(x_{2}\right) \rrbracket_{M, c, g^{\prime s\left[x_{2} \rightarrow c_{w}\right]}, c_{w}, c_{t}}=1$ for exactly one $g^{\prime s\left[x_{2} \rightarrow c_{w}\right]}$ such that $g^{\prime S\left[x_{2} \rightarrow c_{w}\right]}\left[x_{2}\right] c_{g}^{s}$ and

(ii) $\llbracket i f_{x_{1}}\left[W\left(x_{1}\right) \wedge P\left(x_{2}, x_{1}\right)\right]\left[I\left(x_{1}^{f}\right)\right] \rrbracket_{M, c, g^{\prime s\left[x_{2} \rightarrow c_{w}\right]}, c_{w}, c_{t}}$ is defined for every $g^{\prime s\left[x_{2} \rightarrow c_{w}\right]}$ such that $g^{\prime s\left[x_{2} \rightarrow c_{w}\right]}\left[x_{2}\right] c_{g}^{s}$ and $\llbracket K\left(x_{2}\right) \rrbracket_{M, c, g^{\prime s\left[x_{2} \rightarrow c_{w}\right]}, c_{w}, c_{t}}=1$

only if:

(i) and for every $g^{\prime s\left[x_{2} \rightarrow c_{w}\right]}$ such that $g^{\prime s\left[x_{2} \rightarrow c_{w}\right]}\left[x_{2}\right] c_{g}^{s}$ and

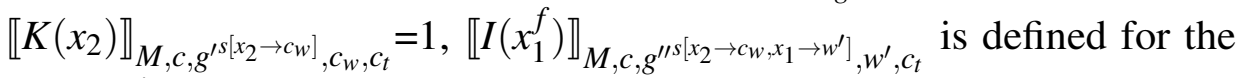
world $w^{\prime}$ which is the world closest to $c_{w}$ such that $\llbracket \exists x_{1}\left[W\left(x_{1}\right) \wedge P\left(x_{2}, x_{1}\right)\right] \rrbracket_{M, c, g^{\prime s\left[x_{2} \rightarrow c_{w}\right]}, w^{\prime}, t}=1$ and every $g^{\prime \prime s\left[x_{2} \rightarrow c_{w}, x_{1} \rightarrow w^{\prime}\right]}$ such that $g^{\prime \prime s\left[x_{2} \rightarrow c_{w}, x_{1} \rightarrow w^{\prime}\right]}\left[x_{1}\right] g^{\prime s\left[x_{2} \rightarrow c_{w}\right]}$ and

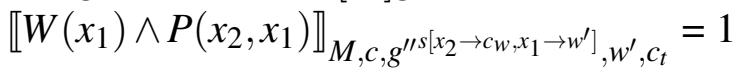

only if: 
Del Prete \& Zucchi

(i) and for every $g^{\prime s\left[x_{2} \rightarrow c_{w}\right]}$ such that $g^{\prime s\left[x_{2} \rightarrow c_{w}\right]}\left[x_{2}\right] c_{g}^{s}$ and

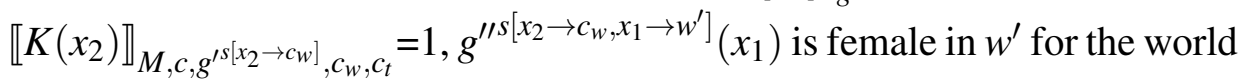
$w^{\prime}$ which is the world closest to $c_{w}$ such that $\llbracket \exists x_{1}\left[W\left(x_{1}\right) \wedge P\left(x_{2}, x_{1}\right)\right] \rrbracket_{M, c, g^{s\left[x_{2} \rightarrow c_{w}\right]}, w^{\prime}, t}=1$ and every $g^{\prime \prime s\left[x_{2} \rightarrow c_{w}, x_{1} \rightarrow w^{\prime}\right]}$ such that $g^{\prime \prime s\left[x_{2} \rightarrow c_{w}, x_{1} \rightarrow w^{\prime}\right]}\left[x_{1}\right] g^{\prime s\left[x_{2} \rightarrow c_{w}\right]}$ and

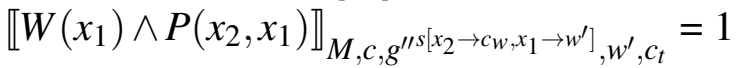

only if:

there is exactly one theory Copernicus proposes in $c_{w}$ and for every individual $x$ and world $w^{\prime}$ such that $x$ is a woman who proposes in $w^{\prime}$ the theory Copernicus proposes in $c_{w}$ and $w^{\prime}$ is the world closest to $c_{w}$ in which a woman proposes the theory Copernicus proposes in $c_{w}, x$ is female in $w^{\prime}$.

Consider now conditional (87b) again:

b. If Copernicus ${ }_{1}$ hadn't existed, we would not praise him ${ }_{1}$ now.

According to our assumption about proper names in section 10.1, (87b) is translated as (93) (for simplicity, we ignore tense and the time indexical "now", and we assume that " $k$ " is the individual constant translating the proper name "Copernicus"):

$$
\text { if } \sim E\left(x_{1}^{k}\right) \sim P\left(\text { we, } x_{1}^{m}\right)
$$

Assuming interpretation (91) for the conditional operator, we derive the definedness conditions in (94a) for (93):

a. $\quad \llbracket$ if $\sim E\left(x_{1}^{k}\right) \sim P\left(w e, x_{1}^{m}\right) \rrbracket_{M, c, c_{g}^{s}, c_{w}, c_{t}}$ is defined only if $\llbracket \sim P\left(\right.$ we, $\left.x_{1}^{m}\right) \rrbracket_{M, c, c_{g}^{s}, w^{\prime}, c_{t}}$ is defined, where $w^{\prime}$ is the world closest to $c_{w}$ such that $\llbracket \sim E\left(x_{1}^{k}\right) \rrbracket_{M, c, c_{g}^{s}, w^{\prime}, c_{t}}=1$ only if $c_{g}^{s}\left(x_{1}\right)$ is male in $c_{w}=s\left(x_{1}\right)$ and $c_{g}^{s}\left(x_{1}\right)$ is identical to Copernicus.

b. $\quad$ if $\llbracket$ if $\sim E\left(x_{1}^{k}\right) \sim P\left(\right.$ we, $\left.x_{1}^{m}\right) \rrbracket_{M, c, c_{g}^{s}, c_{w}, c_{t}}$ is defined, then $\llbracket$ if $\sim E\left(x_{1}^{k}\right) \sim P\left(\right.$ we, $\left.x_{1}^{m}\right) \rrbracket_{M, c, c_{g}^{s}, c_{w}, c_{t}}=1$ if $\llbracket \sim P\left(w e, x_{1}^{m}\right) \rrbracket_{M, c, c_{g}^{s}, w^{\prime}, c_{t}}=1$, where $w^{\prime}$ is the world closest to $c_{w}$ such that $\llbracket \sim E\left(x_{1}^{k}\right) \rrbracket_{M, c, c_{g}^{s}, w^{\prime}, c_{t}}=1$ if $c_{g}^{s}\left(x_{1}\right)$ is male in $c_{w}=s\left(x_{1}\right)$, we do not praise $c_{g}^{s}\left(x_{1}\right)$ in $w^{\prime}$, where $w^{\prime}$ is the world closest to $c_{w}$ such that $c_{g}^{s}\left(x_{1}\right)$ is identical to Copernicus and $c_{g}^{s}\left(x_{1}\right)$ does not inhabit $w^{\prime}$. 
According to (94a), for formula (93) translating (87b) to be defined, the contextual assignment must assign to the pronoun " $\mathrm{him}_{1}$ " an individual who is male in the world of the context and identical to Copernicus. Since Copernicus is a man in the context of utterance of (87b), the condition is met.

If the above observations are correct, our proposal accounts for the interpretation of anaphoric pronouns with non c-commanding antecedents in the conditionals in (87): the behaviour of these pronouns in (87) is consistent with our assumption concerning the role of quantifiers in shifting the modal component of the assignment.

Notice, by the way, that the account we propose for the behavior of pronouns anaphoric to proper names can also explain cases in which pronouns occur in the scope of attitude verbs while being anaphoric to proper names. Consider for instance the following discourse, based on Sharvit (2008):

$\mathrm{John}_{i}$ didn't realize that Bill ${ }_{j}$ was male. $\mathrm{John}_{i}$ thought that he $j \backslash *$ she $_{j}$ liked $\operatorname{him}_{i}$.

Sharvit's observation is that it is odd to use "she" in this discourse. Our proposal predicts the oddness of the female pronoun in (95), since it requires that the descriptive content of "she ${ }_{j}$ " be satisfied by Bill in the world of the context of utterance of (95).

We conclude by pointing out an open problem for our proposal. Consider case (96), based on Yanovich (2010):

(96) Context: The Russian name "Sasha" can be used for both male and female individuals. Suppose that I plan to visit some old friends of mine. I know that they have a kid and that the name of the kid is "Sasha", but I do not know whether it is a girl or a boy.

a. ??Tomorrow, I'll see Sasha. I'll kiss him 1 .

b. ??Tomorrow, I'll see Sasha, I'll kiss her ${ }_{1}$.

Our account can explain the infelicity of (96a)-(96b) in the following way. Suppose that (96a)-(96b) are translated, respectively, as (97a)-(97b) (ignoring the tense and the time adverb):

$$
\begin{array}{ll}
\text { a. } & \operatorname{visit}\left(x_{1}^{s}, I\right) \wedge k i s s\left(x_{1}^{m}, I\right) \\
\text { b. } & \operatorname{visit}\left(x_{1}^{s}, I\right) \wedge \operatorname{kiss}\left(x_{1}^{f}, I\right)
\end{array}
$$

According to our theory, (97a)-(97b) are true in a context if they are true with respect to the assignment of the context, false if they are false with respect to that assignment. No matter how we specify the definedness conditions for conjoined formulae, (97a) is only defined for assignments that assign to the variable $x_{1}$ an individual who is male and is identical to Sasha in the world of the context, while (97b) is only 
defined for assignments that assign to the variable $x_{1}$ an individual who is female and is identical to Sasha in the world of the context. Based on Soames (1989) and Sudo (2012), we introduce the following bridge principle relating semantic presuppositions to pragmatic presuppositions: ${ }^{25}$

The bridge principle. If, in order for the denotation of $S$ to be defined in a context $c, p$ must be the case in the world of $c$, then, for $S$ to be felicitously uttered in $c$, the conversational background of $c$ must entail $p$.

Since, in the context described in (96), the sex of Sasha is not known, the conversational background entails neither that Sasha is female nor that Sasha is male, thus (96a) and (96b) are now predicted to be infelicitous in that context.

Consider, however, the conditionals in (98):

(98) a. If Sasha 1 is male, I'll buy him 1 a doll.

b. If Sasha 2 is female, I'll buy her 2 a toy car.

These conditionals are felicitous if uttered in the context described in (96). Yet, given our semantics, they should behave like conditional (87b) ("If Copernicus 1 hadn't existed, we would not praise him 1 now”). In particular, (98a) should only be defined for assignments that assign to the variable $x_{1}$ an individual who is identical to Sasha and is male in the world of the context, and (98b) should only be defined for assignments that assign to the variable $x_{2}$ an individual who is identical to Sasha and is female in the world of the context. Thus, for (98a) to be defined, Sasha must be male in the world of the context, and for (98b) to be defined, Sasha must be female in the world of the context. Since, in the relevant context, we do not know Sasha's sex, the conversational background of the context fails to entail that Sasha is male, and it also fails to entail that Sasha is female. Therefore, our semantics, paired with the bridge principle, incorrectly predicts that (98a) and (98b) should be infelicitous in the context at hand.

What (98a) and (98b) show is that, contrary to what our semantics for conditionals predicts, if-clauses sometimes act as if they could locally satisfy the gender presuppositions of a free pronoun occurring in the consequent of the conditional - to state this point in the terms of our formal account: the conditional operator in (98) would operate not just on the world of the circumstance, but also on the modal parameter of the assignment of the circumstance, by setting it to a function that maps the pronoun's variable to the world of the antecedent. This is not always the case, as can be seen by comparing the indicative conditional in (98a) to the subjunctive

25 The same principle was implicitly at work in the explanation we proposed for the infelicity of (52) and (65). 
conditionals in (99), uttered in a context in which the conversational participants know that Sasha is female:

(99) a. ??If Sasha 1 were male, we would buy him 1 a toy car.

b. If Sasha 1 were male, we would buy her 1 a toy car.

In (99), as in (87b), the gender presupposition of "him 1 " must be satisfied in the world of the context and cannot be satisfied in the counterfactual world introduced by the antecedent, hence the masculine pronoun in (99a) is not acceptable. Notice that, in this respect, the gender presuppositions of free pronouns behave differently from the presuppositions triggered by other expressions. For example, we observe no similar contrast between indicative and counterfactual conditionals with respect to the possibility of locally satisfying the existence presuppositions of definite descriptions occurring in the consequent, e.g., (100) and (101) are equally acceptable in their respective contexts:

(100) [Context: We don't know whether John has a bike.]

If John has a bike, his bike is Italian.

(101) [Context: We know that John doesn't have a bike.] If John had a bike, his bike would be Italian.

We leave the analysis of (98) as an open problem, to be dealt with in a more comprehensive account.

\section{Previous accounts and the fundamental problem}

Before concluding, we discuss two recent theories of third person pronouns proposed by Paul Elbourne and Angelika Kratzer, and we see how they may deal with the fundamental problem. It should be mentioned that Elbourne, unlike Kratzer, provides no semantics for $\varphi$-features, so in our discussion we will consider what seems to be a natural way of spelling out the semantics of $\varphi$-features in his theory.

Elbourne $(2005,2008)$ presents a situation semantics for third person pronouns that accounts for their bound and deictic uses in a uniform way. On Elbourne's theory, both bound and deictic third person pronouns are interpreted as definite descriptions. In this system, predicate denotations are functions from individual concepts (functions from situations to individuals) to propositions (functions from situations to truth-values), and referential terms denote individual concepts. For instance, "Mary" denotes the constant function that assigns Mary to each situation and "runs" denotes the function that assigns to every individual concept $u$ the (characteristic function of the) set of situations $s$ such that $u(s)$ runs in $s$. Then, 
"Mary runs" denotes the (characteristic function of the) set of situations $s$ such that Mary runs in them:
a. $\llbracket$ Mary $\rrbracket^{g}=\lambda s$. Mary
b. $\quad \llbracket$ runs $\rrbracket^{g}=\lambda u_{<s, e>} . \lambda s . u(s)$ runs in $s$
c. $\quad \llbracket$ Mary runs $\rrbracket^{g}=\lambda s$. Mary runs in $\mathrm{s}$

Definite descriptions denote individual concepts. The definite article is interpreted as in (103a), which yields the denotation in (103c) for "the cat":
a. $\llbracket$ the $\rrbracket^{g}=\lambda f_{<s e, s t>} . \lambda s . x f\left(\lambda s^{\prime} . x\right)(s)=1$
b. $\quad \llbracket$ cat $\rrbracket^{g}=\lambda u_{<s, e>} . \lambda s . u(s)$ is a cat in $s$
c. $\llbracket$ the cat $\rrbracket^{g}=\lambda s$. $x$ x $x$ is a cat in $s$

The expression " $7 \mathrm{x} \mathrm{x}$ is a cat in $\mathrm{s}$ " denotes the unique individual that is a cat in $s$, if there is one, and is undefined otherwise. This Fregean treatment of definite descriptions as referring terms generates the presupposition that there is exactly one cat in $s$ : if this condition is not satisfied, the description lacks a semantic value and thus is infelicitous.

A DP containing "it" is projected at LF as (104a), ${ }^{26}$ where $\mathrm{R}_{m}$ is a variable of type $\langle e,<s e, s t>>$ (a function from individuals to predicate denotations), the index $\mathrm{i}_{n}$ denotes the individual assigned to $\mathrm{n}$ by the assignment $\mathrm{g}$, and "it" has the same denotation as the definite article:

$$
\begin{array}{ll}
\text { a. } & {\left[D P \text { it }\left[{ }_{N P} \mathrm{R}_{m} \mathrm{i}_{n}\right]\right]} \\
\text { b. } & \llbracket \mathrm{i}_{n} \rrbracket^{g}=g(n) \\
\text { c. } & \llbracket \mathrm{it} \rrbracket^{g}=\lambda f_{<s e, s t>} . \lambda s . \\
\end{array}
$$

When the pronoun is used deictically, the contextually supplied property denoted by $\mathrm{R}_{m}$ is the one in (105) below, i.e. the function that assigns to each individual $x$ the predicate denotation that holds of an individual concept in a situation $s$ iff the concept applied to $s$ yields an individual identical to $x$ :

$$
\lambda x . \lambda u_{<s, e>} . \lambda s . u(s)=x
$$

The denotation of the NP is obtained by applying this property to the denotation of the index:

$$
\llbracket \mathrm{R}_{m} \mathrm{i}_{n} \rrbracket^{g}=\lambda u_{<s, e>} \cdot \lambda s . u(s)=g(n)
$$

26 We are relying here on the most recent proposal in Elbourne (2008). Our observations concerning Elbourne's theory, however, carry over to the proposal in Elbourne (2005) as well. 
By applying the denotation of "it" to the NP denotation, we obtain the denotation of the deictic DP, which is the function that maps each situation to the individual identical to the value of the index $\mathrm{i}_{n}$ relative to the assignment $g$ :

$$
\llbracket \text { it }\left[\mathrm{R}_{m} \mathrm{i}_{n}\right] \rrbracket^{g}=\lambda s . x x=g(n)
$$

Assuming that $g$ is provided by the context and assigns to $n$ the individual pointed at, "it runs", in the deictic interpretation of the pronoun, will denote the set of situations in which the individual pointed at in the context runs:

$$
\llbracket\left[\text { it } \mathrm{R}_{m} \mathrm{i}_{n}\right] \text { runs } \rrbracket^{g}=\lambda s . x x=g(n) \text { runs in } s
$$

Bound variable pronouns are dealt with by assuming that the relation variable $\mathrm{R}_{m}$ may be bound at LF. Thus, for instance, the LF for (109a) is given in (109b) (where "THE $\mathrm{R}_{2} \mathrm{i}_{3}$ " is the trace left by the raised subject and THE is a phonologically null definite article):

(109) a. Every diver attacked the shark next to him.

b. [every diver $\lambda_{2}\left[\left[T H E\left[R_{2} i_{3}\right]\right]\right.$ attacked the shark next to [him $\left[R_{2}\right.$ $\left.\left.\left.\left.\mathrm{i}_{3}\right]\right]\right]\right]$

Given the way the rule of predicate abstraction is set up in Elbourne's system, the $\lambda$-expression in (109b) is interpreted as (111) below, which, combined with the interpretation of the quantifier "every diver", gives the correct truth-conditions for (109a):

\section{Predicate abstraction}

For all indices $i$ and assignments $g$,

$\llbracket \lambda_{i} \alpha \rrbracket^{g}=\lambda u_{<s, e>\cdot \llbracket \alpha \rrbracket^{g i d e n t}(u) / i}$,

where ident $(u)=_{\text {def }} \lambda x . \lambda v_{<s, e>} . \lambda s . v(s)=u(s)$

and $g^{\text {ident }(u) / i}$ is the variable assignment that is exactly

like $g$ except that it maps $i$ to $\operatorname{ident}(u)$.

$\lambda u$. $\lambda$ s. $u(s)$ attacked the shark next to $u(s)$ in $s$.

Notice that this way of achieving a unified account is monstrous, since the interpretation of bound pronouns requires $\lambda$-abstraction over the variable $\mathbf{R}_{m}$, whose value is fixed by a contextually provided assignment, and thus amounts to shifting a contextual parameter.

As we mentioned above, Elbourne does not provide a treatment of $\varphi$-features for third person pronouns in his semantics. Following his way of generating the presuppositions for the definite article, we may generate the presupposition that the referent of "he" is male by assuming the following clause: 


$$
\llbracket \text { he } \rrbracket^{g}=\lambda f_{<s e, s t>} \cdot \lambda s . x\left(x \text { is male in } s \text { and } f\left(\lambda s^{\prime} . x\right)(s)=1\right)
$$

By (112), we predict that in the deictic use, the semantic value of the pronoun is only defined in a situation $s$ if the individual pointed at (the individual assigned to the index by the contextually provided assignment) is male in $s$ :

$$
\llbracket \text { he }\left[\mathbf{R}_{m} \mathbf{i}_{n}\right] \rrbracket^{g}=\lambda s . x(x \text { is male in } s \text { and } x=g(n))
$$

The problem is that (112) gets the interaction of deictic pronouns with modal operators wrong, since it predicts that one could utter (42) while pointing at a female individual to claim that that individual is a male university professor in some possible situation:

(42) He could have been a university professor.

Indeed, if the possibility modal in (42) takes widest scope at LF, then by the interpretation in $(114 b)^{27}$, we get the denotation in (114d) for (42):
a. $\quad\left[\diamond\left[\left[D P\right.\right.\right.$ he $\left.\left[\mathrm{R}_{m} \mathrm{i}_{n}\right]\right]$ university prof. $\left.]\right]$
b. $\llbracket \diamond \rrbracket^{g}=\lambda p . \lambda s$. there is a world $w$ accessible from $s$ such that $p(w)=$ 1 .
c. $\quad$ university prof. $\rrbracket^{g}=\lambda u . \lambda s . u(s)$ is a university prof. in $s$.
d. $\llbracket(114 \mathrm{a}) \rrbracket^{g}=\lambda s$. there is a world $w$ accessible from $s$ such that $x(x$ is male in $w$ and $x=g(n))$ is a university prof. in $w$.

To avoid this unwelcome result, the alternative option for "he" is to assume that its descriptive content must be satisfied in the world of the context $c_{w}$ :

$$
\llbracket \text { he } \rrbracket^{g, c}=\lambda f_{<s e, s t>} . \lambda s . x\left(x \text { is male in } c_{w} \text { and } f\left(\lambda s^{\prime} . x\right)(s)=1\right)
$$

In this case, however, we incorrectly predict for (37) that the descriptive content of the pronoun "he" namely the property of being a human male, must be satisfied in the world of the context:

(37) It could have been that every US gold medalist ${ }_{i}$ had defeated a Russian who challenged $\operatorname{him}_{i}$.

Indeed, in this case, the $\lambda$-expression in (116a) is interpreted as (116b):

(116) a. $\diamond$ [every US gold medalist $\lambda_{2}\left[\left[\operatorname{THE}\left[\mathrm{R}_{2} \mathrm{i}_{3}\right]\right]\right.$ defeated a Russian who challenged [him $\left.\left.\left.\left[\mathrm{R}_{2} \mathrm{i}_{3}\right]\right]\right]\right]$

27 This interpretation is the one assumed in Elbourne (2013). 
Unified semantics for pronouns

b. $\quad \lambda u . \lambda s . u(s)$ defeated a Russian who challenged in $s$ y $(y$ is male in $c_{w}$ and $\left.y=u(s)\right)$.

Given the interpretation of "every" in (117), we get the denotation in (118) for $(116 a):^{28}$

$\llbracket$ every $\rrbracket^{g}=\lambda f_{<s e, s t>} \cdot \lambda g_{<s e, s t>} . \lambda s$. for every $x$ such that $f(\lambda s . x)(s)=1$, $g(\lambda s . x)(s)=1$.

(118) $\lambda s$. there is a world $w$ accessible from $s$ such that for every $x$ such that $x$ is a US gold medalist in $w, x$ defeated in $w$ a Russian who challenged in $w x y$ ( $y$ is male in $c_{w}$ and $y=x$ ).

The function from situations to truth-values in (118) is defined only for situations for which there is an accessible world $w$ such that for every $\mathrm{x}$ that is a US gold medalist in $w$, there is an individual identical to $\mathrm{x}$ who is male in the world of the context. Thus, Elbourne's theory, under a straightforward way of spelling out the interpretation of $\varphi$-features, runs into the fundamental problem. ${ }^{29,30}$

28 Elbourne's denotation for "every" quantifies over minimal situations in order to account for donkey anaphora. For sake of simplicity, we ignore this aspect of his definition.

29 An alternative way of generating the presuppositions of gender features in Elbourne's account is to assume that they introduce restrictions on the NP denotation the pronoun combines with at LF. For example, we might assume the following interpretation for "he":

$$
\begin{aligned}
& \llbracket h e \rrbracket^{g, c}=\lambda f_{<s e, s t>} \text { : for every } u_{<s, e>} \text { for every } s(f(u)(s)=1 \supset \\
& \text { male } \left.(u)\left(c_{w}\right)=1\right) . \lambda s . \imath x f\left(\lambda s^{\prime} . x\right)(s)=1
\end{aligned}
$$

Then, again, we get the fundamental problem back, since, according to this interpretation, the property of being male must be met in the world of the context also when the pronoun is bound.

30 In the semantics proposed in Elbourne (2013), unlike in the one considered here, descriptions no longer carry an index ranging over individuals, but carry a pronoun ranging over situations (the situation pronoun). The semantics of pronominal DPs in that system is identical to that of descriptions, the only difference being that in pronominal DPs the NP complement is phonologically null:

$$
\begin{array}{ll}
\text { a. } & {\left[[\text { the NP }] \mathrm{s}_{i}\right]} \\
\text { b. } & {\left[[\text { it NP }] \mathrm{s}_{i}\right]}
\end{array}
$$

With intensional operators, de relde dicto readings of descriptions may be obtained by manipulating the situation pronoun. If this pronoun remains free in the scope of the intensional operator, we get a de $r e$ reading, while the de dicto reading is obtained by binding it with the $\varsigma$ operator. For example, the de dicto reading of the description in (31) is represented as in (ii) below, where $\varsigma$ binds the situation pronoun in such a way that the sentence in the scope of $\diamond$ denotes the characteristic function of the set of situations $s$ such that there is a unique man wearing the gold medal in $s$ and that man is American in $s$ :

The man wearing the gold medal could have been an American. 
Kratzer (2009) does not provide a uniform account of third person pronouns in our sense, since she posits a different semantics for referential pronouns and pronouns that are genuinely bound. Thus, for instance the pronoun "she" may be projected at LF either as (119a) or as (119b), where (119a) corresponds to the referential pronoun and (119b) to the bound pronoun:

(119) a. $\quad\left[D P[\right.$ Num singular $]\left[[D\right.$ Def $]\left[{ }_{N}\right.$ female $\left.\left.]\right]\right]$

b. $\quad[D P[$ Num singular $][[D][N \mathrm{n}]]]$

The interpretation of the features in (119a)-(119b) is specified as follows (where $\sigma$ is Link's (1983) operator, which maps a property of individuals to the maximal element that has that property):

$$
\begin{array}{ll}
\text { a. } & \llbracket[N \mathrm{n}] \rrbracket^{g, c}=g(\mathrm{n}) . \\
\text { b. } & \llbracket[D \text { Def }] \rrbracket^{g, c}=\lambda P_{e, t} . \sigma x P(x) . \\
\text { c. } & \llbracket[N \text { female }]]^{g, c}=\lambda x \cdot x \text { is one or more females. } \\
\text { d. } & \llbracket[\text { Num singular }] \rrbracket^{g, c}=\lambda x: x \text { is an atom. } x
\end{array}
$$

In this account, genuinely bound pronouns are minimally born as mere indices ${ }^{31}$ and they can inherit the $\varphi$-features of their binders in the PF component. As these features are not visible to the semantic component of the grammar, they are not interpreted. The fact that bound pronouns surface as the same vocabulary elements as referential pronouns is then explained by the fact that, by feature transmission, bound pronouns may end up bearing the same $\varphi$-features as referential pronouns at $\mathrm{PF}$, and these features are targeted by vocabulary insertion rules.

In her proposal, Kratzer does not discuss the interaction of third person pronouns with modal operators. Let's extend Kratzer's system in the standard way by assuming that denotation, besides being relative to a context and an assignment, as Kratzer assumes, is also relative to a situation. Since in Kratzer's approach the semantics of referential pronouns differs from that of bound pronouns, the problem of blocking indexical presuppositions for genuinely bound pronouns does not arise. Let's see

(ii) $\quad \diamond\left[\varsigma_{i}\left[\left[[\right.\right.\right.$ the man wearing the gold medal $\left.] \mathrm{s}_{i}\right]$ is an american $\left.]\right]$

The problem, again, is that, if we generate the presupposition that the referent of "he" is male by assuming the clause in (iii), we incorrectly predict that the presupposition of "he" in (33) may be satisfied in the world introduced by the possibility operator:

$$
\left.\llbracket[\text { he NP }] \mathrm{s}_{i}\right] \rrbracket^{g}=\lambda \operatorname{s.x}\left(x \text { is male in } s \text { and } \llbracket \mathrm{NP} \rrbracket^{g}(x)=1\right)
$$

He could have been an American.

31 According to Kratzer, bound pronouns may also be born with some $\varphi$-features provided that they give rise to interpretable DPs. 
why. For sake of discussion, let's assume the following simplified version of the semantics of the possibility operator:

$$
\llbracket \diamond \rrbracket^{g, c, s}=\lambda p \text {. there is a situation } s^{\prime} \text { such that } p\left(s^{\prime}\right)=1 .
$$

Now the familiar dilemma arises, namely we have to decide whether the property of being female in the denotation of the feature [female] must be satisfied in the situation of evaluation as in (122a) or in the utterance situation, as in (122b):

a. $\quad \llbracket[N$ female $] \rrbracket^{g, c, s}=\lambda x . x$ is one or more females in $s$.

b. $\quad \llbracket[N$ female $] \rrbracket^{g, c, s}=\lambda x . x$ is one or more females in $c_{s}$.

In order to account for the interaction of referential pronouns with modal operators illustrated by (33) above, we must choose (122b): in this way, the denotation of the referential pronoun "she" ends up being defined only if in the utterance situation of "she" there is a unique individual who is female. However, as this modification only affects the interpretation of referential pronouns and not of bound pronouns, we do not expect that the same kind of indexical presupposition should carry over to bound pronouns, which is a welcome prediction.

The fundamental problem still arises for (123) though:

It could have been that every US gold medalist ${ }_{i}$ had defeated a Russian who challenged her ${ }_{i}$.

Indeed, in (123) the gender feature of the pronoun "her" cannot be inherited by feature transmission, since there is no female antecedent construed with the pronoun. Thus, "her" must be born with the [female] feature, which is then visible to the semantic component. Since in Kratzer's system the descriptive feature [female] cannot semantically combine with the denotation of a numerical index to yield a DP denotation, the pronoun "her" in (123) must project as (119a), namely "her" in (123) is not a truly bound pronoun, but a D-type pronoun. If "her" is interpreted as (119a), then by (122b) we expect its denotation to be defined only if the property of being female is satisfied by an individual in the situation of utterance, thus generating an incorrect indexical presupposition. In other words, while Kratzer's account avoids the fundamental problem for pronouns that are genuinely bound, it still runs into the problem for cases like (123), which, according to her theory, are only prima facie instances of binding.

\section{Conclusions}

Kaplan's (1977) goal was to provide a semantics for demonstrative uses of third person pronouns and other indexicals. Bound variable uses of third person pronouns 
were explicitly excluded from his investigation. Indeed, Kaplan suggested that demonstrative and bound variable uses of "he" involve distinct lexical items that happen to be homonyms:

... I began my investigations by asking what is said when a speaker points at someone and says, "He is suspicious". The word 'he', so used, is a demonstrative...

The group of words for which I propose a semantical theory includes the pronouns 'I', 'my', 'you', 'he', 'his', 'she', 'it', the demonstrative pronouns 'that', 'this', the adverbs 'here', 'now', 'tomorrow', 'yesterday', the adjectives 'actual', 'present', and others. These words have uses other than those in which I am interested (or, perhaps, depending on how you individuate words, we should say that they have homonyms in which I am not interested). For example, the pronouns 'he' and 'his' are used not as demonstratives but as bound variables in

For what is a man profited, if he shall gain the whole world, and lose his own soul?

(Kaplan 1977: 489-90)

As we pointed out at the start, the hypothesis that demonstrative and bound variable uses of "he" involve distinct lexical items leaves unexplained why in language after language the same phonological word is used both as a demonstrative and as a bound variable. This observation provides a good reason not to concede the homonym hypothesis, or at least not to concede it without putting up a fight. In this paper, we assumed that Kaplan, when uttering a demonstrative "he", and King James's translator, when uttering a bound pronoun "he", were uttering the same word both from a phonological and from a semantic point of view, not just homonyms.

We explored an account of the semantics of this word which does not require quantifiers to be monsters and which is based on the idea that variable assignments occur both as coordinates of the context and as coordinates of the circumstance of evaluation. According to this account, non anaphoric free third-person pronouns are no longer indexical in Kaplan's sense: as for its reference, a third-person pronoun depends on a coordinate of the circumstance of evaluation, i.e. on the variable assignment $g^{s}$ of the circumstance, and not directly on any aspect of the context. The fact that its value ends up being determined by the context is a byproduct of the definition of truth in context, that equates the variable assignment of the context with the variable assignment of the circumstance. In MacFarlane's (2009) terms, this amounts to saying that non anaphoric free third-person pronouns are context sensitive, since they have different denotations relative to different contexts of use, 
but not indexical, since their content does not vary from context to context. The fact that the denotation of third person pronouns depends on the assignment coordinate of the circumstance opens up the possibility that third person pronouns may not have a contextually determined reference whenever they are in the scope of operators that shift the assignment of the circumstance. We argued that quantifiers are such operators.

We proposed that, for an account of this sort to work properly (in particular, for it to avoid generating unwanted indexical presuppositions for bound pronouns), one should assume that variable assignments have a modal component, and thus they perform two tasks: not only do they assign individuals to variables but they also assign worlds to variables (that is, to each variable $v$ they associate information concerning the "modal localization" of the individual assigned to $v$ ). We tested the empirical coverage of the theory and we saw that it accounts for several core cases of interaction of pronouns with intensional operators. As it might be expected, we also found some cases in which the theory needs to be refined further.

\section{Appendix: The formal system}

In this appendix, we state the formal system in its final form.

\section{The intensional language IL}

\section{Symbols}

$c_{1}, c_{2}, c_{3}, \ldots$ (individual constants)

$x_{1}, x_{2}, x_{3}, \ldots$ (plain variables)

$x_{1}^{m}, x_{2}^{m}, x_{3}^{m}, \ldots$ (presuppositional variables)

$x_{1}^{f}, x_{2}^{f}, x_{3}^{f}, \ldots$ (presuppositional variables)

$x_{1}^{n}, x_{2}^{n}, x_{3}^{n}, \ldots$ (presuppositional variables)

$x_{1}^{c_{1}}, x_{1}^{c_{2}}, x_{1}^{c_{3}}, \ldots x_{2}^{c_{1}}, x_{2}^{c_{2}}, x_{2}^{c_{3}}, \ldots$ (presuppositional variables)

$P_{1}^{1}, P_{2}^{1}, \ldots, P_{1}^{2}, P_{2}^{2} \ldots$ (predicates)

$\wedge, \sim, \vee$, every, the, a, if, $\diamond, \square, B$, believe, $E$ (logical constants)

Formulae Let $\mathscr{V}$ be the set of plain variables and $\mathscr{V}^{*}$ the set of variables (plain and presuppositional). 
i. If $\mathrm{P}^{n}$ is an n-place predicate and $\tau_{i}, \ldots \tau_{j}$ are $\mathrm{n}$ terms (variables or constants), $\mathrm{P}^{n}\left(\tau_{i}, \ldots \tau_{j}\right)$ is a wff.

ii. If $\Phi$ and $\Psi$ are wffs, then $\ulcorner\sim \Phi\urcorner,\ulcorner\Phi \wedge \Psi\urcorner,\ulcorner\Phi \vee \Psi\urcorner\ulcorner$ if $\Phi \Psi\urcorner,\ulcorner\diamond \Phi\urcorner,\ulcorner\square \Phi\urcorner$ are wffs.

iii. if $\Phi$ and $\Psi$ are wffs and $v \in \mathscr{V},\ulcorner$ every $v \Phi \Psi\urcorner,\ulcorner$ the $\nu \Phi \Psi\urcorner,\ulcorner a v \Phi \Psi\urcorner$ are wffs.

iv. If $\tau$ is a term and $\Phi$ is a wff, $\left\ulcorner B_{\tau} \Phi\right\urcorner$ is a wff.

v. If $\tau$ is a term and $\Phi$ is a wff, $\ulcorner$ believe $(\tau, \Phi)\urcorner$ is a wff.

vi. If $\tau$ is a term, $\ulcorner E(\tau)\urcorner$ is a wff.

Models A model for IL is a structure $M=<\mathscr{C}, \mathscr{W}, \mathscr{U}, \mathscr{T}, \mathscr{P}, \mathscr{I}, \mathscr{F}>$, where

i. $\mathscr{C}$ is a nonempty set (the set of contexts), where if $c \in \mathscr{C}$,

(i) $c_{a} \in \mathscr{U}$ (the agent of $c$ )

(ii) $c_{t} \in \mathscr{T}$ (the time of $c$ )

(iii) $c_{p} \in \mathscr{P}$ (the position of $c$ )

(iv) $c_{w} \in \mathscr{W}$ (the world of $c$ )

(v) $c_{g}^{s} \in \mathscr{U}^{\mathscr{V}}$ (the assignment of $c$ ), where $s \in \mathscr{W}^{\mathscr{V}}$ and $s(v)=c_{w}$ for every $v \in \mathscr{V}$.

(vi) $c_{R} \in \mathscr{W} \times \mathscr{W}($ an accessibility relation)

ii. $\mathscr{W}$ is a nonempty set (the set of worlds)

iii. $\mathscr{U}$ is a nonempty set (the set of individuals)

iv. $\mathscr{T}$ is a nonempty set (the set of times)

v. $\mathscr{P}$ is a nonempty set (the set of positions)

vi. $\mathscr{I} \in \wp(\mathscr{U})^{\mathscr{W}}$ (a function that assigns to each world $w \in \mathscr{W}$ the set of individuals in $\mathscr{U}$ inhabiting world $w$ )

vii. $\mathscr{F}$ is a function that to every triple consisting of an $\mathrm{n}$-place predicate $\mathrm{P}^{n}$, a world, and a time, assigns a set of $n$-tuples of members of $\mathscr{U}$, and to every individual constant assigns a member of $\mathscr{U}$. 
Unified semantics for pronouns

Denotation The denotation of an expression is relative to a model, a context of utterance, and a circumstance of evaluation consisting of a world, a time, and a variable assignment $g^{s}$, where $g^{s} \in \mathscr{U}^{\mathscr{V}}$ and $s \in \mathscr{W}^{\mathscr{V}}$.

We use " $\llbracket \alpha \rrbracket_{M, c, g^{s}, w, t}$ " as short for "the denotation of $\alpha$ in the context $c$ relative to the circumstance $<g^{s}, w, t>$ ".

We use " $g^{\prime s\left[v_{i} \rightarrow w, \ldots, v_{j} \rightarrow w^{\prime}\right]}\left[v_{i}, \ldots, v_{j}\right] g^{s "}$ as short for "the assignment $g^{\prime s\left[v_{i} \rightarrow w, \ldots, v_{j} \rightarrow w^{\prime}\right]}$ is identical to $g^{s}$ except for the fact that (i) $g^{\prime s\left[v_{i} \rightarrow w, \ldots, v_{j} \rightarrow w^{\prime}\right]}$ may differ from $g^{s}$ because its modal component assigns the world $w$ to the variable $v_{i}$, $\ldots$, and the world $w^{\prime}$ to the variable $v_{j}$ and (ii) $g^{s\left[v_{i} \rightarrow w, \ldots, v_{j} \rightarrow w^{\prime}\right]}$ may differ from $g^{s}$ for the individuals assigned to $v_{i}, \ldots, v_{j}$ ".

Here we specify the denotations for a selected set of expressions:

i. $\llbracket c_{i} \rrbracket_{M, c, g^{s}, w, t}=\mathscr{F}\left(c_{i}\right)$.

ii. $\llbracket \mathrm{P}^{n} \rrbracket_{M, c, g^{s}, w, t}=\mathscr{F}\left(\mathrm{P}^{n}\right)(w)(t)$.

iii. $\llbracket x_{i} \rrbracket_{M, c, g^{s}, w, t}=g^{s}\left(x_{i}\right)$, where $g^{s}\left(x_{i}\right) \in \mathscr{I}\left(s\left(x_{i}\right)\right)$ (i.e., the individual $g^{s}\left(x_{i}\right)$ inhabits the world $s\left(x_{i}\right)$ ).

iv. $\llbracket x_{i}^{m} \rrbracket_{M, c, g^{s}, w, t}=g^{s}\left(x_{i}\right)$ if $g^{s}\left(x_{i}\right)$ is human and male in $s\left(x_{i}\right)$, and it's undefined otherwise.

v. $\llbracket x_{i}^{f} \rrbracket_{M, c, g^{s}, w, t}=g^{s}\left(x_{i}\right)$ if $g^{s}\left(x_{i}\right)$ is human and female in $s\left(x_{i}\right)$, and it's undefined otherwise.

vi. $\llbracket x_{i}^{n} \rrbracket_{M, c, g^{s}, w, t}=g^{s}\left(x_{i}\right)$ if $g^{s}\left(x_{i}\right)$ is non-human in $s\left(x_{i}\right)$, and it's undefined otherwise.

vii. $\llbracket x_{i}^{c_{i}} \rrbracket_{M, c, g^{s}, w, t}=g^{s}\left(x_{i}\right)$ if $g^{s}\left(x_{i}\right)=\llbracket c_{i} \rrbracket_{M, c, g^{s}, w, t}$, and it's undefined otherwise.

viii. Suppose $\llbracket \tau_{i} \rrbracket_{M, c, g^{s}, w, t}, \ldots, \llbracket \tau_{j} \rrbracket_{M, c, g^{s}, w, t}$ are defined.

Then $\llbracket \mathrm{P}^{n}\left(\tau_{i}, \ldots, \tau_{j}\right) \rrbracket_{M, c, g^{s}, w, t}=1$ if $<\llbracket \tau_{i} \rrbracket_{M, c, g^{s}, w, t}, \ldots, \llbracket \tau_{j} \rrbracket_{M, c, g^{s}, w, t}>\in \mathscr{F}\left(\mathrm{P}^{n}\right)(w)(t)$; $\llbracket \mathrm{P}^{n}\left(\tau_{i}, \ldots, \tau_{j}\right) \rrbracket_{M, c, g^{s}, w, t}=0$ if $<\llbracket \tau_{i} \rrbracket_{M, c, g^{s}, w, t}, \ldots, \llbracket \tau_{j} \rrbracket_{M, c, g^{s}, w, t}>\notin \mathscr{F}\left(\mathrm{P}^{n}\right)(w)(t)$.

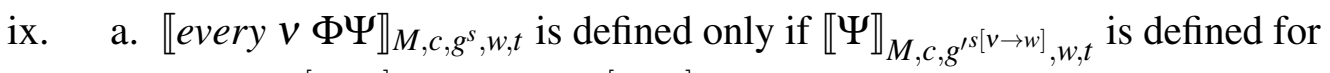
every $g^{\prime s[v \rightarrow w]}$ such that $g^{\prime s[v \rightarrow w]}[v] g^{s}$ and $\llbracket \Phi \rrbracket_{M, c, g^{\prime s[v \rightarrow w]}, w, t}=1$.

b. if $\llbracket$ every $v \Phi \Psi \rrbracket M, c, g^{s}, w, t$ is defined, then:

$\llbracket$ every $v \Phi \Psi \rrbracket_{M, c, g^{s}, w, t}=1$ if $\llbracket \Psi \rrbracket_{M, c, g^{\prime s[v \rightarrow w]}, w, t}=1$ for every $g^{s[v \rightarrow w]}$

such that $g^{\prime s[v \rightarrow w]}[v] g^{s}$ and $\llbracket \Phi \rrbracket_{M, c, g^{\prime s[v \rightarrow w]}, w, t}=1$;

otherwise $\llbracket e v e r y v \Phi \Psi \rrbracket_{M, c, g^{s}, w, t}=0$.

x. $\quad$ a. $\llbracket$ the $v \Phi \Psi \rrbracket_{M, c, g^{s}, w, t}$ is defined only if 
i. $\llbracket \Phi \rrbracket_{M, c, g^{s[v \rightarrow w]}, w, t}=1$ for exactly one $g^{\prime s[v \rightarrow w]}$ such that $g^{\prime s[v \rightarrow w]}[v] g^{s}$ and

ii. $\llbracket \Psi \rrbracket_{M, c, g^{\prime s[v \rightarrow w]}, w, t}$ is defined for every $g^{\prime s[v \rightarrow w]}$ such that $g^{\prime s[v \rightarrow w]}[v] g^{s}$ and $\llbracket \Phi \rrbracket_{M, c, g^{s}[v \rightarrow w]}, w, t=1$.

b. if $\llbracket$ the $v \Phi \Psi \rrbracket_{M, c, g^{s}, w, t}$ is defined, then:

$\llbracket$ the $v \Phi \Psi \rrbracket_{M, c, g^{s}, w, t}=1$ if $\llbracket \Psi \rrbracket_{M, c, g^{\prime s[v \rightarrow w]}, w, t}=1$ for every $g^{s[v \rightarrow w]}$ such that $g^{\prime s[v \rightarrow w]}[v] g^{s}$ and $\llbracket \Phi \rrbracket_{M, c, g^{\prime s[v \rightarrow w]}, w, t}=1$;

otherwise $\llbracket$ the $v \Phi \Psi \rrbracket_{M, c, g^{s}, w, t}=0$.

xi. $\quad$ a. $\llbracket a \vee \Phi \Psi \rrbracket_{M, c, g^{s, w, t}}$ is defined only if $\llbracket \Psi \rrbracket_{M, c, g^{s[v \rightarrow w]}, w, t}$ is defined for some $g^{g^{[[v \rightarrow w]}}$ such that $g^{\prime s[v \rightarrow w]}[v] g^{s}$ and $\llbracket \Phi \rrbracket_{M, c, g^{\prime S[v \rightarrow w]}, w, t}$

$=1$.

b. if $\llbracket a \vee \Phi \Psi \rrbracket_{M, c, g^{s}, w, t}$ is defined, then:

$\llbracket a \vee \Phi \Psi \rrbracket_{M, c, g^{s}, w, t}=1$ if $\llbracket \Psi \rrbracket_{M, c, g^{s[v \rightarrow w]}, w, t}=1$ for some $g^{s[v \rightarrow w]}$ such

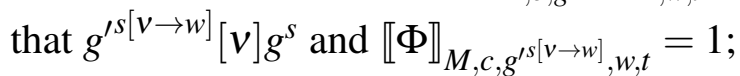

otherwise $\llbracket a v \Phi \Psi \rrbracket_{M, c, g^{s}, w, t}=0$.

xii. $\quad$ a. $\llbracket \diamond \varphi \rrbracket_{M, c, g^{s}, w, t}$ is defined only if $\llbracket \varphi \rrbracket_{M, c, g^{s}, w^{\prime}, t}$ is defined for all $w^{\prime} \in \mathscr{W}$ such that $w c_{R} w^{\prime}$.

b. if $\llbracket \triangleright \varphi \rrbracket_{M, c, g^{s}, w, t}$ is defined, then:

$\llbracket \diamond \varphi \rrbracket_{M, c, g^{s}, w, t}=1$ if $\llbracket \varphi \rrbracket_{M, c, g^{s}, w^{\prime}, t}=1$, for some $w^{\prime} \in \mathscr{W}$ such that $w c_{R} w^{\prime}$

$\llbracket \diamond \varphi \rrbracket_{M, c, g^{s}, w, t}=0$ if $\llbracket \varphi \rrbracket_{M, c, g^{s}, w^{\prime}, t}=0$, for all $w^{\prime} \in \mathscr{W}$ such that $w c_{R} w^{\prime}$.

xiii. a. $\llbracket i f \Phi \Psi \rrbracket_{c, g^{s}, w, t}$ is defined only if $\llbracket \Psi \rrbracket_{c, g^{s}, w^{\prime}, t}$ is defined, where $w^{\prime}$ is the world closest to $w$ such that $\llbracket \Phi \rrbracket_{c, g^{s}, w^{\prime}, t}=1$.

b. if $\llbracket i f \Phi \Psi \rrbracket_{c, g^{s}, w, t}$ is defined, then:

$\llbracket$ if $\Phi \Psi \rrbracket_{c, g^{s}, w, t}=1$ if $\llbracket \Psi \rrbracket_{c, g^{s}, w^{\prime}, t}=1$, where $w^{\prime}$ is the world closest to $w$ such that $\llbracket \Phi \rrbracket_{c, g^{s}, w^{\prime}, t}=1$; otherwise $\llbracket i f \Phi \Psi \rrbracket_{c, g^{s}, w, t}=0$.

xiv. $\quad$ a. $\llbracket B_{\tau} \varphi \rrbracket_{M, c, g^{s}, w, t}$ is defined only if $\llbracket \varphi \rrbracket_{M, c, g^{s}, w^{\prime}, t}$ is defined for every $w^{\prime} \in$ $\mathscr{W}$ which is a belief world of $\llbracket \tau \rrbracket_{M, c, g^{s}, w, t}$ in $w$.

b. if $\llbracket B_{\tau} \varphi \rrbracket_{M, c, g^{s}, w, t}$ is defined, then:

$\llbracket B_{\tau} \varphi \rrbracket_{M, c, g^{s}, w, t}=1$ if $\llbracket \varphi \rrbracket_{M, c, g^{s}, w^{\prime}, t}=1$, for every $w^{\prime} \in \mathscr{W}$ which is a belief world of $\llbracket \tau \rrbracket_{M, c, g^{s}, w, t}$ in $w$;

$\llbracket B_{\tau} \varphi \rrbracket_{M, c, g^{s}, w, t}=0$ if $\llbracket \varphi \rrbracket_{M, c, g^{s}, w^{\prime}, t}=0$, for some $w^{\prime} \in \mathscr{W}$ which is a belief world of $\llbracket \tau \rrbracket_{M, c, g^{s}, w, t}$ in $w$. 
Unified semantics for pronouns

xv. a. $\llbracket$ believe $(\tau, \varphi) \rrbracket_{M, c, g^{s}, w, t}$ is defined only if $\llbracket \varphi \rrbracket_{M, c, g^{s}, w^{\prime}, t}$ is defined, for every $w^{\prime} \in \mathscr{W}$ which is a belief world of $\llbracket \tau \rrbracket_{M, c, g^{s}, w, t}$ in $w$

b. if $\llbracket$ believe $(\tau, \varphi) \rrbracket_{M, c, g^{s}, w, t}$ is defined, then:

$\llbracket$ believe $(\tau, \varphi) \rrbracket_{M, c, g^{s}, w, t}=1$ if $\llbracket \varphi \rrbracket_{M, c, g^{s}, w^{\prime}, t}=1$,

for every $w^{\prime} \in \mathscr{W}$ which is a belief world of $\llbracket \tau \rrbracket_{M, c, g^{s}, w, t}$ in $w$; $\llbracket$ believe $(\tau, \varphi) \rrbracket_{M, c, g^{s}, w, t}=0$ if $\llbracket \varphi \rrbracket_{M, c, g^{s}, w^{\prime}, t}=0$,

for some $w^{\prime} \in \mathscr{W}$ which is a belief world of $\llbracket \tau \rrbracket_{M, c, g^{s}, w, t}$ in $w$.

xvi. $\llbracket E(\tau) \rrbracket_{M, c, g^{s}, w, t}=1$ if $\llbracket \tau \rrbracket_{M, c, g^{s}, w, t} \in \mathscr{I}(w)$; $\llbracket E(\tau) \rrbracket_{M, c, g^{s}, w, t}=0$ if $\llbracket \tau \rrbracket_{M, c, g^{s}, w, t} \in \overline{\mathscr{I}(w)}$.

\section{Truth in context}

- $\Phi$ is true in a context $c$, in the model $M$, if $\llbracket \Phi \rrbracket_{M, c, c_{g}^{s}, c_{w}, c_{t}}=1$,

- $\Phi$ is false in a context $c$, in the model $M$, if $\llbracket \Phi \rrbracket_{M, c, c_{g}^{s}, c_{w}, c_{t}}=0$,

- $\Phi$ is neither true nor false in a context $c$, in the model $M$, if $\llbracket \Phi \rrbracket_{M, c, c_{g}^{s}, c_{w}, c_{t}}$ is undefined.

\section{References}

Anand, Pranav \& Andrew Nevins. 2004. Shifty operators in changing contexts. In Kazuha Watanabe \& Robert B. Young (eds.), Semantics and Linguistic Theory (SALT) 14, 20-37. Ithaca, NY: CLC Publications. http://dx.doi.org/10.3765/salt. v14i0.2913.

Bach, Emmon \& Robin Cooper. 1977. The NP-S analysis of relative clauses and compositional semantics. Linguistics and Philosophy 2(1). 145-149. http://dx. doi.org/10.1007/BF00365132.

Cable, Seth. 2005. Binding local person pronouns without semantically empty features. Ms. University of Massachusetts at Amherst. http://people.umass.edu/ scable/papers/binding-local-pronouns.pdf.

Charlow, Simon \& Yael Sharvit. 2014. Bound 'de re' pronouns and the LFs of attitude reports. Semantics \& Pragmatics 7(3). 1-43. http://dx.doi.org/10.3765/sp.7.3.

Chierchia, Gennaro. 1989. Anaphora and attitudes de se. In Renate Bartsch, Johan F. A. K. van Benthem \& Peter van Emde Boas (eds.), Semantics and contextual expression, 1-30. Foris. http://dx.doi.org/10.1007/978-94-015-6932-3.

Clements, George N. 1975. The logophoric pronoun in Ewe: Its role in discourse. Journal of West African Languages 10(2). 141-177.

Cooper, Robin. 1983. Quantification and syntactic theory. Dordrecht: Reidel. 
Cumming, Sam. 2008. Variabilism. The Philosophical Review 117(4). 525-554. http://dx.doi.org/10.1215/00318108-2008-015.

Elbourne, Paul. 2005. Situations and individuals. Cambridge, MA: The MIT Press.

Elbourne, Paul. 2008. Demonstratives as individual concepts. Linguistics and Philosophy 31(4). 409-466. http://dx.doi.org/10.1007/s10988-008-9043-0.

Elbourne, Paul. 2013. Definite descriptions. Oxford University Press. http://dx.doi. org/10.1093/acprof:oso/9780199660193.001.0001.

Evans, Gareth. 1977. Pronouns, quantifiers and relative clauses (1). The Canadian Journal of Philosophy 7(3). Reprinted in: Evans, G., 1985, Collected papers, Dordrecht: Foris, pp. 76-152, 467-536. http://dx.doi.org/10.1080/00455091. 1977.10717030.

Evans, Gareth. 1980. Pronouns. Linguistic Inquiry 11(2). 337-362.

Fodor, Janet Dean. 1970. The linguistic description of opaque contexts. Boston, MA: Massachusetts Institute of Technology dissertation.

Groenendijk, Jeroen \& Martin Stokhof. 1991. Dynamic predicate logic. Linguistics and Philosophy 14(1). 39-100. http://dx.doi.org/10.1007/BF00628304.

Heim, Irene. 1982. The semantics of definite and indefinite noun phrases. Published in 1989 by Garland, New York. Amherst, MA: University of Massachusetts dissertation.

Heim, Irene. 1992. Presupposition projection and the semantics of attitude verbs. Journal of Semantics 9(3). 183-221. http://dx.doi.org/10.1093/jos/9.3.183.

Heim, Irene. 2008. Features on bound pronouns. In Daniel Harbour, David Adger \& Susana Bejar (eds.), Phi theory: Phi-features across modules and interfaces, 35-56. Oxford University Press.

Heim, Irene \& Angelika Kratzer. 1998. Semantics in generative grammar. Oxford: Blackwell.

Kamp, Hans. 1981. A theory of truth and semantic representation. In Jeroen Groenendijk, Theo Janssen \& Martin Stokhof (eds.), Formal methods in the study of language, 277-322. Reprinted in J. Groenendijk, T. Janssen, and M. Stokhof (eds.), Truth, interpretation and information. Foris, Dordrecht, 1984. Amsterdam: Mathematical Centre.

Kaplan, David. 1977. Demonstratives. Manuscript, University of California at Los Angeles. Published in Almog, J., Perry, J., and Wettstein, H. K., editors, Themes from Kaplan, 1989, pages 481-563. Oxford University Press, Oxford.

Kaplan, David. 1989. Afterthoughts. In John Almog, John Perry \& Howard K. Wettstein (eds.), Themes from Kaplan, 565-614. Oxford: Oxford University Press.

Karttunen, Lauri. 1974. Presupposition and linguistic context. Theoretical Linguistics 1(1-3). 181-194. http://dx.doi.org/10.1515/thli.1974.1.1-3.181. 
Unified semantics for pronouns

Keshet, Ezra. 2008. Good intensions: Paving two roads to a theory of the de re/de dicto distinction. Boston, MA: Massachusetts Institute of Technology dissertation.

Keshet, Ezra. 2011. Split intensionality: A new scope theory of de re and de dicto. Linguistics and Philosophy 33(4). 251-283. http://dx.doi.org/10.1007/s10988011-9081-x.

Kratzer, Angelika. 2009. Making a pronoun: Fake indexicals as windows into the properties of pronouns. Linguistic Inquiry 40(2). 187-237. http://dx.doi.org/10. 1162/ling.2009.40.2.187.

Lewis, David K. 1980. Index, context, and content. In S. Kanger \& S. Öhman (eds.), Philosophy and grammar, 79-100. Dordrecht: Reidel. http://dx.doi.org/10.1007/ 978-94-009-9012-8_6.

Link, Godehard. 1983. The logical analysis of plurals and mass terms. In Rainer Bäuerle, Christoph. Schwarze \& Arnim von Stechow (eds.), Meaning, use and interpretation of language, 302-323. Berlin: De Gruyter. http://dx.doi.org/10. 1515/9783110852820.302.

MacFarlane, John. 2009. Nonindexical contextualism. Synthese 166(2). 231-250. http://dx.doi.org/10.1007/s11229-007-9286-2.

Montague, Richard. 1973. A proper treatment of quantification in ordinary English. In Jaako Hintikka, Julius Moravçsik \& Patrick Suppes (eds.), Approaches to natural language: Proceedings of the 1970 Stanford workshop on grammar and semantics, 221-242. Also published in Richard Thomason (ed.) Formal philosophy, Yale University Press, New Haven, CT, 1974. Dordrecht: Reidel. http://dx.doi.org/10.1007/978-94-010-2506-5_10.

Partee, Barbara Hall. 1984. Nominal and temporal anaphora. Linguistics and Philosophy 7. 243-286. http://dx.doi.org/10.1007/BF00627707.

Partee, Barbara Hall. 1997. Genitives - a case study. In Johan van Benthem \& Alice ter Meulen (eds.), Handbook of logic and language, 464-470. Amsterdam: Elsevier. http://dx.doi.org/10.1016/B978-044481714-3/50011-4.

Percus, Orin. 2000. Constraints on some other variables in syntax. Natural Language Semantics 8(3). 173-229. http://dx.doi.org/10.1023/A:1011298526791.

Pickel, Bryan. 2013. Variables and attitudes. Noûs 49(2). http://dx.doi.org/10.1111/ nous. 12044.

Quine, Willard Van Orman. 1956. Quantifiers and propositional attitudes. The Journal of Philosophy 53(5). 177-187. http://dx.doi.org/10.2307/2022451.

Rabern, Brian. 2013. Monsters in Kaplan's logic of demonstratives. Philosophical Studies 164(2). First published online: 28 January 2012. http://dx.doi.org/10. 1007/s11098-012-9855-1.

Romoli, Jacopo \& Yasutada Sudo. 2008. De relde dicto ambiguity and presupposition projection. In Arndt Riester \& Torgrim Solstad (eds.), Sinn und Bedeutung 
(SuB) 13, vol. 2, 425-438. Stuttgart: Online Publikationsverbund der Universität Stuttgart (OPUS).

Schlenker, Philippe. 2003. A plea for monsters. Linguistics and Philosophy 26(1). 29-120. http://dx.doi.org/10.1023/A:1022225203544.

Schlenker, Philippe. 2004. Context of thought and context of utterance: A note on free indirect discourse and the historical present. Mind \& Language 19(3). 279-304. http://dx.doi.org/10.1111/j.1468-0017.2004.00259.x.

Schlenker, Philippe. 2011. Indexicality and de se reports. In Klaus von Heusinger, Claudia Maienborn \& Paul Portner (eds.), Semantics - an international handbook of natural language meaning, vol. 2, 1561-1604. De Gruyter. http://dx.doi.org/ 10.1515/9783110255072.1561.

Schwager, Magdalena. 2009. Speaking of qualities. In Ed Cormany, Satoshi Ito \& David Lutz (eds.), Semantics and Linguistic Theory (SALT) 19, 395-412. Linguistic Society of America. http://dx.doi.org/10.3765/salt.v19i0.2534.

Sharvit, Yael. 2008. The puzzle of free indirect discourse. Linguistics and Philosophy 31(3). 353-395. http://dx.doi.org/10.1007/s10988-008-9039-9.

Soames, Scott. 1989. Presupposition. In Dov Gabbay \& Franz Guenthner (eds.), Handbook of philosophical logic, First, vol. IV, 553-616. Dordrecht: Reidel. http://dx.doi.org/10.1007/978-94-009-1171-0_9.

Stalnaker, Robert C. 1988. Belief attribution and context. In Robert Grimm \& Daniel Merrill (eds.), Contents of thought. Reprinted in Robert Stalnaker, Context and content, Oxford University Press, Oxford, 1999. Tucson: University of Arizona Press.

Stanley, Jason. 2000. Context and logical form. Linguistics and Philosophy 23(4). 391-434. http://dx.doi.org/10.1023/A:1005599312747.

Strawson, Peter Frederick. 1950. On referring. Mind 59(235). 320-344. http://dx. doi.org/10.1093/mind/LIX.235.320.

Sudo, Yasutada. 2012. On the semantics of phi features on pronouns. Boston, MA: Massachusetts Institute of Technology dissertation.

Yanovich, Igor. 2010. On the nature and formal analysis of indexical presuppositions. In Kumiyo Nakakoji, Yohei Murakami \& Eric McCready (eds.), New frontiers in artificial intelligence: Jsai-isai workshops, lenls, jurisin, kcsd, lili, tokyo, japan, november 19-20, 2009, revised selected papers, 272-291. Springer Berlin Heidelberg. http://dx.doi.org/10.1007/978-3-642-14888-0_22.

Zimmermann, Thomas Ede. 1991. Kontextabhängigkeit. In Arnim von Stechow \& Dieter Wunderlich (eds.), Semantik/semantics: Ein internationales Handbuch der zeitgenössischen Forschung / an international handbook of contemporary research, 151-229. Berlin: de Gruyter. 
Unified semantics for pronouns

Fabio Del Prete

Sandro Zucchi

CLLE-ERSS UMR 5263

Dipartimento di Filosofia

Università degli Studi di Milano

党

Université de Toulouse Le Mirail

via Festa del Perdono 7

5, allées Antonio Machado

20122 Milano

31058 Toulouse Cedex 9

France

Italy

fabio.del-prete@univ-tlse2.fr

alessandro.zucchi@unimi.it 